\title{
Beaded lacewings - a pictorial identification key to the genera, their biogeographics and a phylogentic analysis (Insecta: Neuroptera: Berothidae)
}

\author{
Ulrike Aspöck ${ }^{1,2}$, Susanne Randolf ${ }^{1}$ \\ 1 Natural History Museum Vienna, 2nd Zoological Department, Burgring 7, 1010 Vienna, Austria \\ 2 University of Vienna, Department of Integrative Zoology, Althanstrasse 14, 1090 Vienna, Austria
}

http://zoobank.org/A804D00A-5D41-4150-B277-38D1FBB2DC45

Corresponding author: Ulrike Aspöck (ulrike.aspoeck@nhm-wien.ac.at)

Received 28 October 2014

Accepted 26 November 2014

Published 2 December 2014

Academic editor:

Dominique Zimmermann

\section{Key Words}

Berothidae

genera

identification key

distribution maps

biogeography

cladistic analyses

phylogeny

\begin{abstract}
The present paper comprises the first illustrated key for the genera of the Berothidae. Distribution maps for all genera are provided and distribution areas are discussed. A phylogenetic analysis based on the matrix of morphological characters of Aspöck and Nemeschkal (1998) using additional taxa and a modified approach concerning the homology of the genital sclerites (Aspöck and Aspöck 2008) yielded the following conflicting results: (i) The Trichomatinae are nested within the Nosybinae - which is considered an implausible position. (ii) Within the Berothinae, the genus Podallea appeared as the sister group of Asadeteva + Nodalla, whereas previously it was the sister group of the Isoscelipteron clade. In addition, the phylogenetic relevance of a peculiar phenomenon concerning the sclerites of the seventh abdominal segment of the females is discussed.
\end{abstract}

\section{Introduction}

The Berothidae Handlirsch, 1908, are a small neuropteran family that comprises about 110 known species in 24 genera. The adults superficially resemble hemerobiids (Fig. 1) but can clearly be distinguished from them by a pair of large haired tubercles on the vertex and the long "running" CuA of the hindwing (Tjeder 1959). The term beaded refers to the encrusted appearance of the setae on the wings of females that is caused by a secretion (Penny et al. 1997).

The fossil record of Berothidae dates back as far as the Middle Jurassic, but the family is assumed to be much older (Makarkin et al. 2011). Most of the fossil material was described from the Cretaceous e.g. in Lebanese amber (Whalley 1980), Burmese amber (Engel and Grimaldi 2008), New Jersey amber (Grimaldi 2000) and Canadian amber (Klimaszewski and Kevan 1986). The fossil record from the Tertiary is comparatively poor, and only a few berothids are known from Baltic and English ambers (Krüger 1923, Wedmann et al. 2013). A list of known fossil Berothidae is provided in Makarkin et al. (2011).

The biology of the family is poorly documented. Since the adults are almost exclusively collected at light they are assumed to be nocturnal (Aspöck 1986, Oswald et al. 2002). However, Lomamyia Banks, 1904, has been collected by sweeping bushes (Toshi 1964) and was observed to sit inactive on the stems or undersides of leaves (New 1986). Also numerous adults of Nyrma kervillea Navás, 1933 were observed feeding in the daytime (Dobosz and Górski 2008), and species of the genera Nosybus Navás, 1910, and Podallea Navás, 1933, were frequently observed in cocoa plantations and on other vegetation on a field trip in Ghana in 2007 


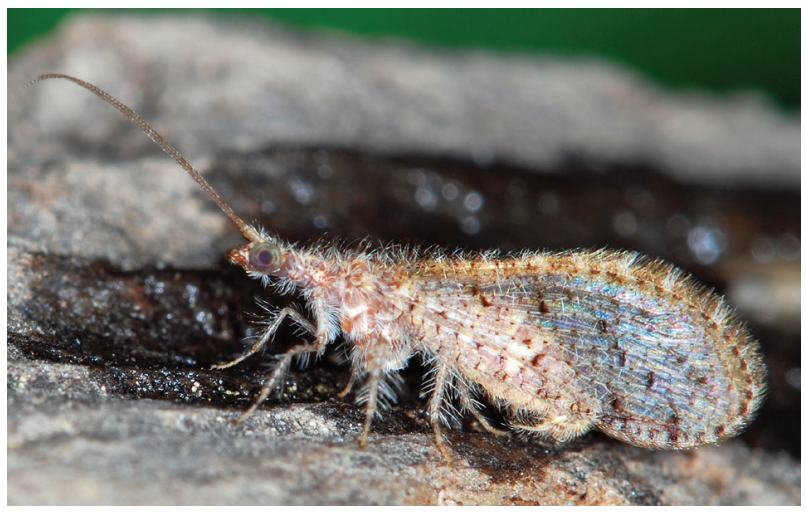

Figure 1. Nodalla sp., q (Photo: Harald Bruckner).

(U. Aspöck, H. Aspöck, Duelli and Hölzel unpublished). Berothidae are polyphagous, their gut usually contains pollen, fragments of small arthropods and fungal hyphae (Monserrat 2006). Pollen is consumed from various inflorescences, e.g. Podallea manselli U. Aspöck \& H. Aspöck, 1988, feeds on Rosaceae and Fabaceae, and Nyrma kervillea on Compositae type Bellis and Umbelliferae (Monserrat 2006, Dobosz and Górski 2008). Even pollen of Monocotyledonae is utilized since Nodalla (Nodalla) saharica (Esben-Petersen, 1920) feeds on Liliaceae (Monserrat 2006).

Larvae are known only from four genera of the subfamily Berothinae (Lomamyia, Isoscelipteron Costa, 1863, Podallea, Spermophorella Tillyard, 1916) and from two genera of the subfamily Nyrminae (Nyrma Navás, 1933, Berothimerobius Monserrat \& Deretzky, 1999) (Tillyard 1916, Gurney 1947, Toschi 1964, Tauber and Tauber 1968, Brushwein 1987, Minter 1990, Möller 2003, Möller et al. 2006, Monserrat 2006, Dobosz and Górski 2008, Komatsu 2014). Their whole life cycle is largely obscure. Larvae of Lomamyia, Podallea and Isoscelipteron are associated with termites in their larval stage (Tauber and Tauber 1968, Brushwein 1987, Minter 1990, Möller et al. 2006, Komatsu 2014), but it is doubtful, whether this is a general strategy of the family or of the subfamily Berothinae only (Wedmann et al. 2013) as no data on the larvae of the other subfamilies are available.

The first modern treatment of the family Berothidae was completed by MacLeod and Adams (1967); it replaced the traditional typological classification and recognized four subfamilies: Cyrenoberothinae MacLeod \& Adams, 1967, Rhachiberothinae Tjeder, 1959 (recently raised to family status, see below), Nosybinae MacLeod \& Adams, 1967, and Berothinae Handlirsch, 1908. Aspöck (1989) erected an additional subfamily, Nyrminae Navás, 1933, to contain the highly specialized species Nyrma kervillea, which was previously placed in the Hemerobiidae.

The first computerized cladistic analysis of the Berothidae (Aspöck and Nemeschkal 1998) yielded two additional subfamilies: Protobiellinae Aspöck \& Nemeschkal, 1998, and Trichomatinae Tillyard, 1916. However, a basal trichotomy of Nyrma, Manselliberotha U. Aspöck \& H. Aspöck, 1988, and Cyrenoberotha MacLeod \& Adams, 1967, remained unresolved and failed to corroborate recognization of the subfamilies Nyrminae and Cyrenoberothinae, which were however retained as a working hypothesis.

The Rhachiberothinae were primarily described as a subfamily of the Berothidae (Tjeder 1959, 1968), later interpreted to be a subfamily of the Mantispidae (Willmann 1990), and finally elevated to family rank as sister group of the Berothidae within the clade Dilaridae + (Mantispidae + (Berothidae + Rhachiberothidae)) (Aspöck and Mansell 1994). Although this arrangement could not be re-established in a molecular analysis of the Neuropterida (Haring and Aspöck 2004), the sister group relationship Berothidae + Rhachiberothidae was corroborated in the phylogenetic analyses of morphological characters by Aspöck et al. (2001), Beutel et al. (2010), Zimmermann et al. (2011), Randolf et al. $(2013,2014)$ and in the treatment of genital sclerites by Aspöck and Aspöck (2008).

The present approach is based on the matrix of Aspöck and Nemeschkal (1998), amended by a new homologization of male and female genital sclerites (Aspöck and Aspöck 2008) and the data for three additional genera: Ormiscocerus Blanchard, 1851, which was rediscovered by Penny and Winterton (2007), Berothimerobius, which was newly described by Monserrat and Deretsky (1999) and Tanzanberotha U. Aspöck \& Hynd, 1995. Tanzanberotha was not included in the analysis of Aspöck and Nemeschkal (1998) because females were unknown, but it was suggested to be part of Nosybinae (Aspöck and Nemeschkal 1998). Females are still unknown, but the genus was included in the present analysis to test if male characters corroborate Tanzanberotha as part of the Nosybinae.

Berothidae occur throughout most biogeographical regions. Cyrenoberothinae are known from southern South America and southern Africa, Nosybinae from the Afrotropical region and South America, Berothinae from most parts of the world with a high diversity in Australia and Africa (Grimaldi and Engel 2005). Nyrminae are known from Anatolia (Aspöck 1989) and Chile (Penny and Winterton 2007, Monserrat and Deretsky 1999). In the present paper the Berothimerobiinae with the single genus Berothimerobius are interpreted to be part of the Nyrminae [nov. syn.!]. The Protobiellinae are restricted to New Zealand and Australia, and the Trichomatinae to Australia (Aspöck and Nemeschkal 1998, Grimaldi and Engel 2005).

Until now the only identification keys available are for the species of a single genus (e.g. Ardila-Camacho 2013, Winterton 2010) or for the genera or species of a single geographic region (e.g. Aspöck et al. 2013). The present work gives an identification key for all known genera of the Berothidae for the first time. In addition, distribution maps of the genera based on data from literature are provided.

\section{Material and methods}

\section{Key}

Figures 2-46 and 56-57 were drawn with Adobe Illustrator CS 11.0.0. For the figures in the identification keys 
already published figures served as template (Tab. 1, Supplementary file 1) except Figures 19, 22 and 23, which were drawn from photographs of the material in the collection of the Natural History Museum Vienna. The identifying characteristics used in the key are highlighted in grey and/or marked with an arrow.

\section{Distribution maps}

Localities were taken from original literature (Supplementary file 2) and listed continuously with a number for each locality in MS Excel 2010 (Supplementary file 3). Plausible locations were set in MS Encarta Professional 2004 (version 13.0.0.0531) and then transferred to copies of Encarta maps with Photoshop Elements 8 (version 8.0) since these cannot bee illustrated in Encarta directly. Some of the location marks are super-imposed due to the vicinity of the localities.

\section{Cladistic analyses}

The phylogenetic analysis comprises 50 characters for 24 genera and 5 outgroup taxa. The character matrix of As- pöck and Nemeschkal (1998) was amended to account for newly available data: the homologized characters of the genital sclerites (Aspöck and Aspöck 2008) and data for Ormiscocerus, Berothimerobius and Tanzanberotha from the literature (Penny and Winterton 2007, Monserrat and Deretsky 1999, Aspöck and Hynd 1995). The matrix is consistent on the genus level (Supplementary file 4).

Only informative characters were included in the data matrix. The cladistic analyses were performed with TNT (Goloboff et al. 2008). Space for 500000 trees was reserved in the memory. Analyses were performed under equal and implied weights. For implied weighting (Goloboff 1993), the concavity constant K was set from 3 - 15 . For each weighting scheme, traditional analyses with 10 000 replications and TBR saving 20 trees per replication were conducted. The root was Nallachius (Dilaridae). Bootstrap values and the Bremer support values were calculated with heuristic search (100 000 replications, 1000 TBR branch swapping replications). For character optimization Winclada (Nixon 2002) was used.

A list of the currently known valid genera and species of Berothidae is provided (Supplementary file 5).

\section{Results}

\section{Key to the genera of Berothidae}

AUSTRALIA and NEW ZEALAND (Figs 2-16, 47, 48, 54, 55)

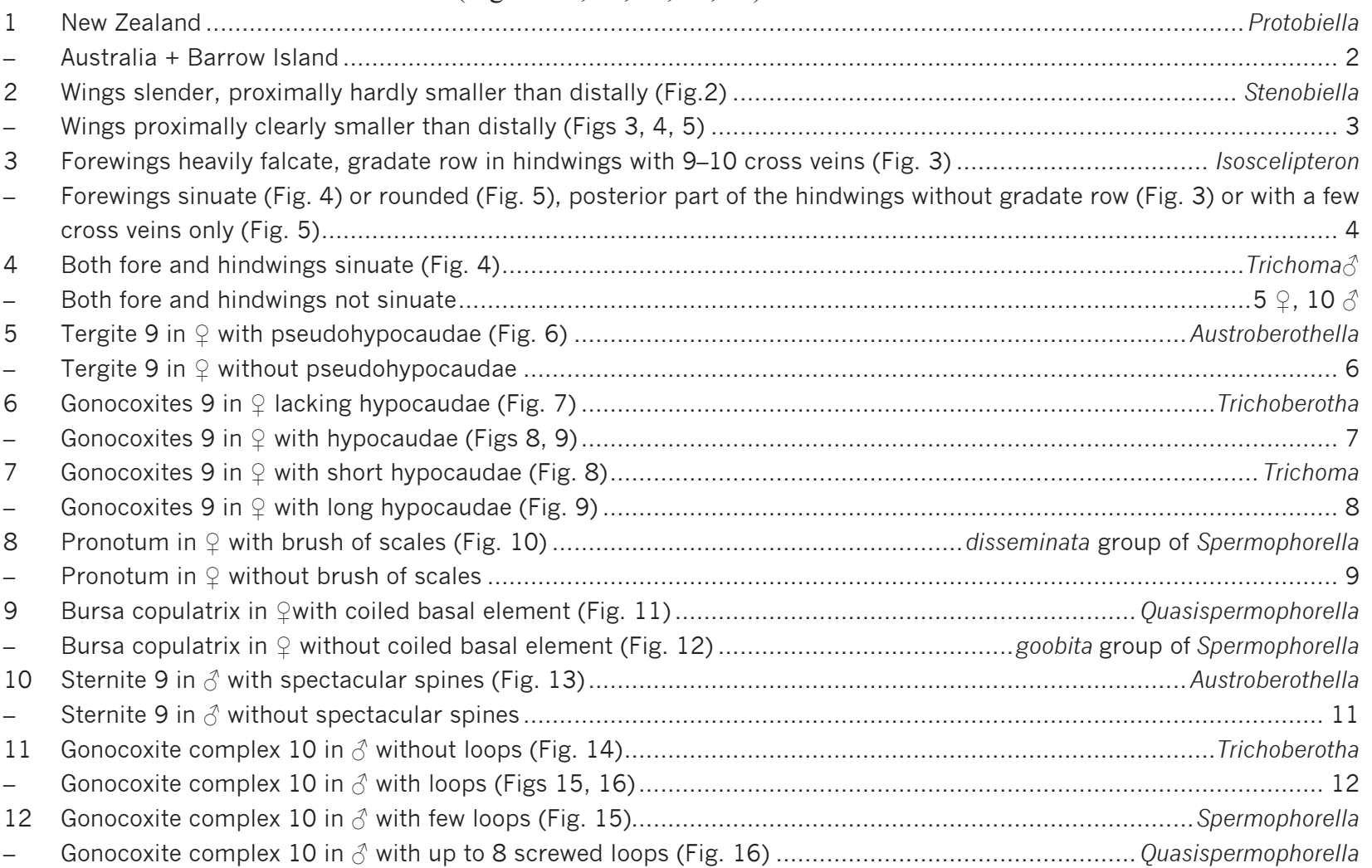

\section{OLD WORLD}

Oriental region (Figs 17-19, 49, 54, 55)

1 Forewing falcate (e.g. Fig. 3) or sinuate (e.g. Fig. 4). 
- $\quad$ Forewing not falcate or sinuate 3

2 Forewing: pterostigma inconspicuous (e.g. Fig. 3)......

Isoscelipteron

Forewing: pterostigma dark, distally enlarged (Fig. 17)

Berotha

3 Postocular region globular (Fig. 18).

Lekrugeria

- Postocular region not globular (Fig. 19)..... Nodalla

\section{OLD WORLD}

Palaearctic region (Figs 20-24, 50, 54, 55)

1 Frons elongated (Fig. 20), forewing venation reticulate (Fig. 21) ……................................................... Nyrma

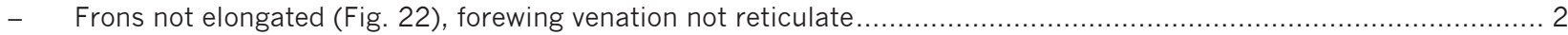

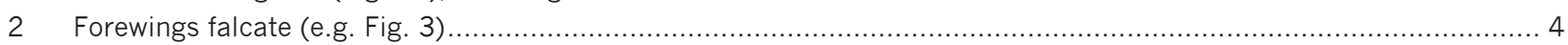

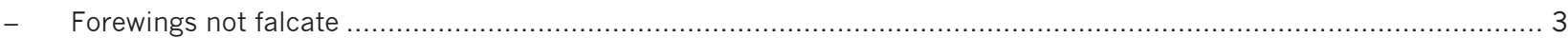

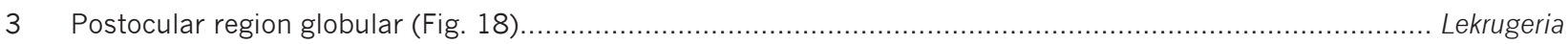

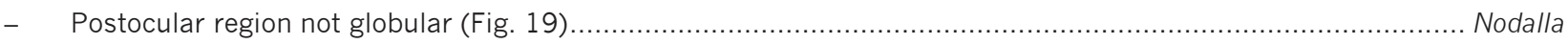

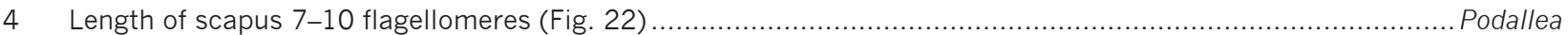

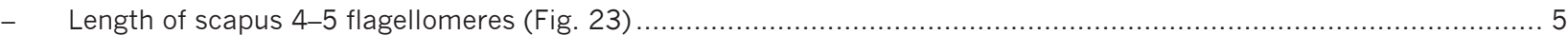

5 Hindwings: gradate row with up to 10 cross veins (e.g. Fig. 3) ................................................... Isoscelipteron

- Posterior part of the hindwings without gradate row (e.g. Fig. 4) or with a few cross veins only (Fig. 24).........Asadeteva

\section{OLD WORLD}

Afrotropical region (Figs 22-34, 51, 52, 55)

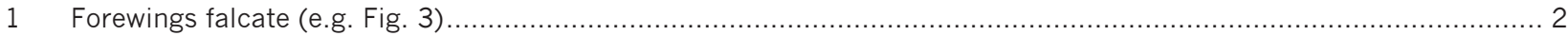

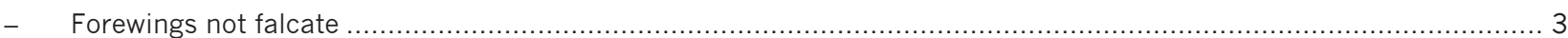

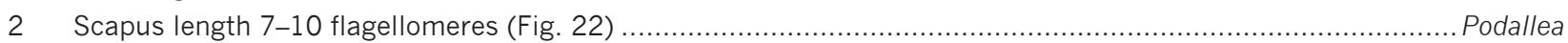
[females: spectacular spermatheca complex (Fig. 25); males: spectacular gonocoxit complex 10 (Fig. 26)]

- $\quad$ Scapus length 4 flagellomeres (Fig. 27)... Berlekrumyia [females: spermatheca complex simple (Fig. 28); males: gonocoxit complex 10 simple (Fig. 29)]

3 Frons elongated (Fig. 30)

- $\quad$ Frons not elongated (Fig. 31)

Manselliberotha

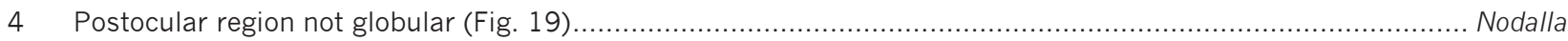

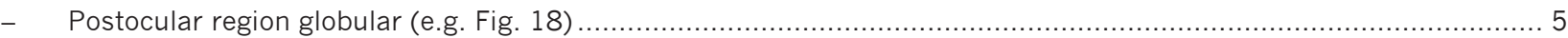

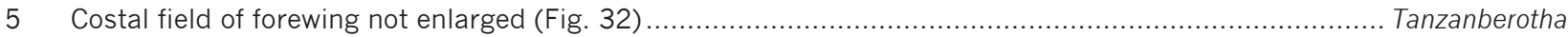

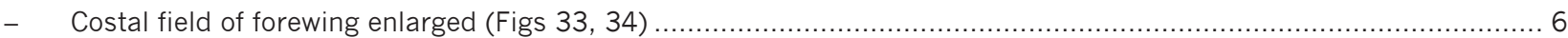

$6 \quad$ Forewing with gradate row (Fig. 33) ................................................................................................. Lekrugeria

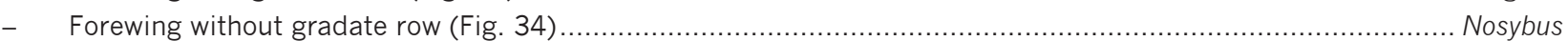

\section{NEW WORLD}

Nearctic region, Neotropical region (Figs 35-46, 53, 55)

1 Forewing venation reticulate (Fig. 35) ......................................................... Ormiscocerus/Berothimerobius

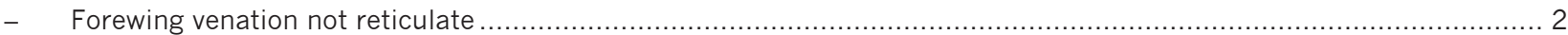

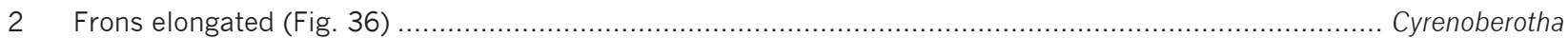

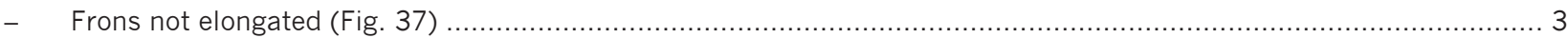

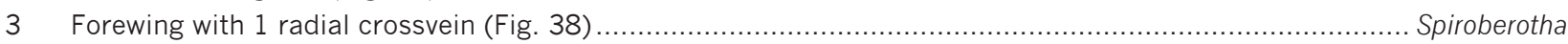
[female: hypocaudae long, finger like (Fig. 39); male: gonocoxite complex 10 coiled (Fig. 40)]

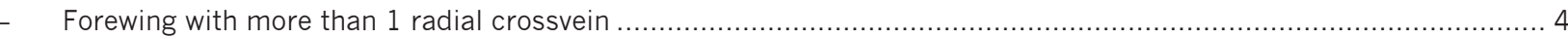

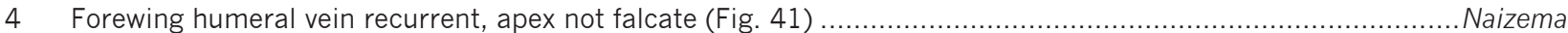
[female: hypocaudae short, wart like (Fig. 42), male: gonocoxit complex 10 coiled (Fig. 43)]

- $\quad$ Forewing humeral vein not recurrent, apex falcate (Fig.44) ...............................................................Lomamyia [female: hypocaudae long, finger like (Fig. 45), male: gonocoxit complex 10 not coiled (Fig. 46)]

\section{Phylogenetically relevant characters}

1. Frons: short (0), elongate (1), see Aspöck and Nemeschkal (1998, char. 0).

2. Mouthparts, position: external (0), sunken into concavity of head (1), see Aspöck and Nemeschkal (1998; char. 1).
3. Mouthparts, shortening: no shortening (0), shortening (1), see Aspöck and Nemeschkal (1998; char. 2).

4. Galea, elongation: not longer than stipes (0), longer than stipes (1), see Aspöck and Nemeschkal (1998; char. 3). 


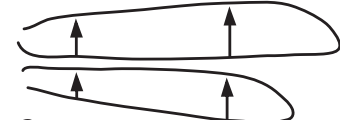

2

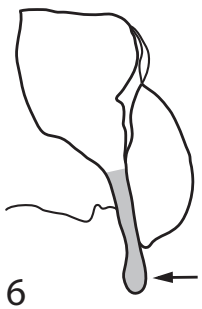

6

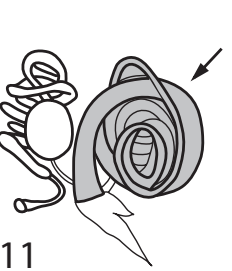

11

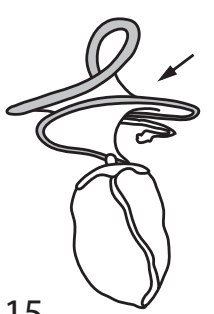

15

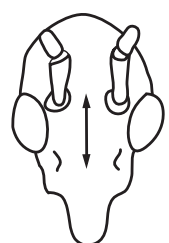

20

7

16
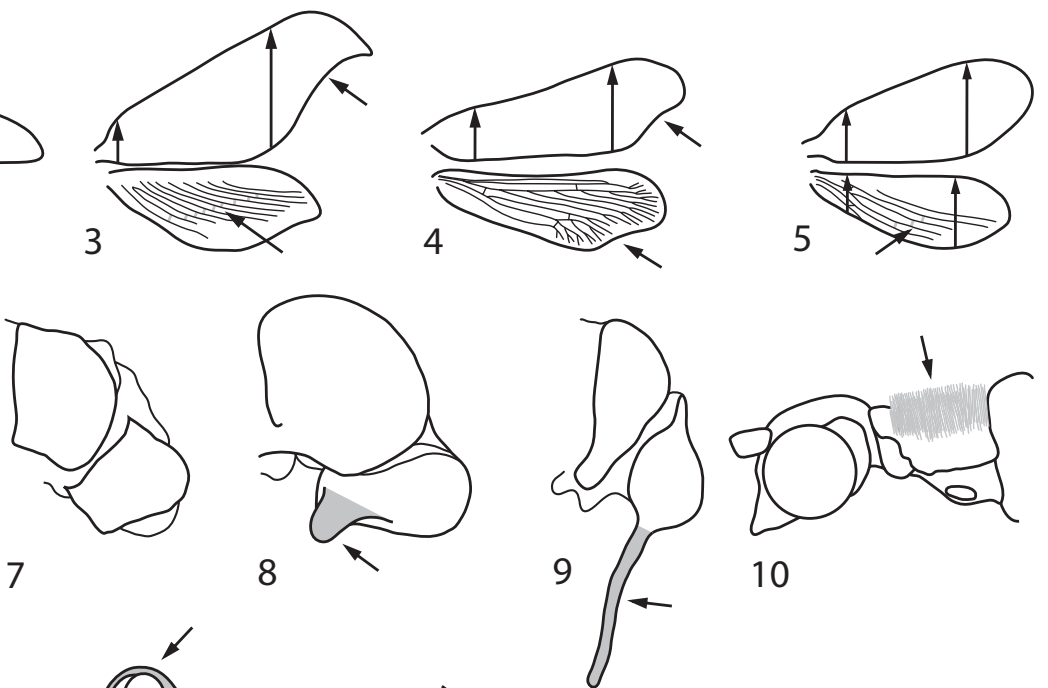

10

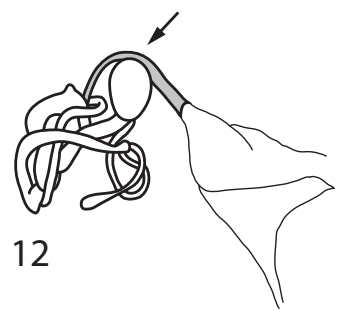

13
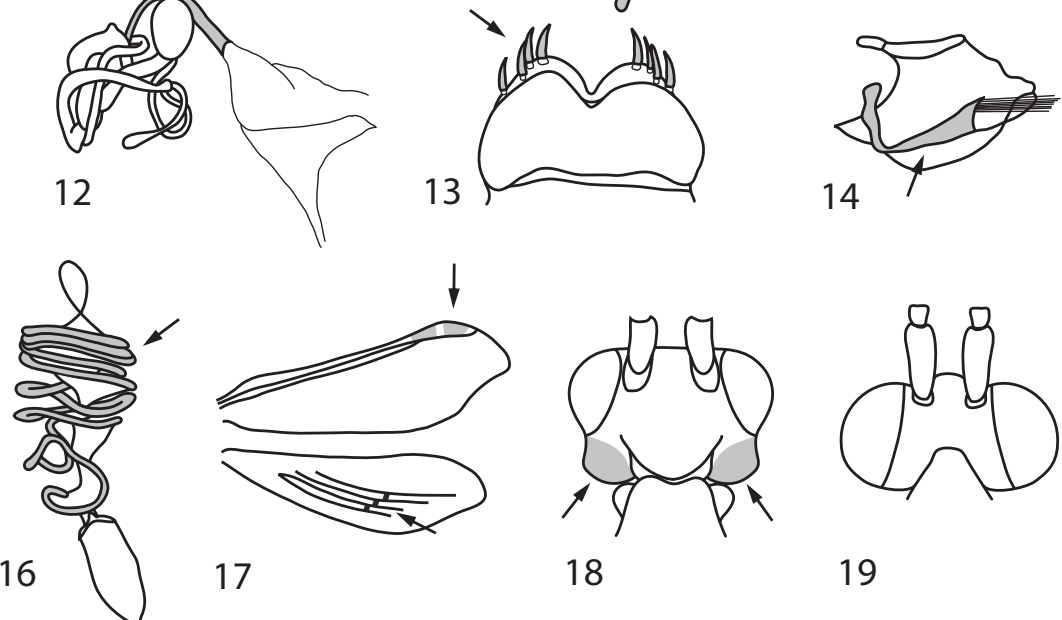

17

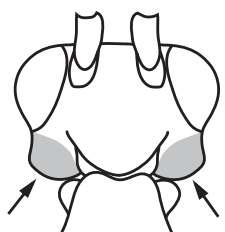

18

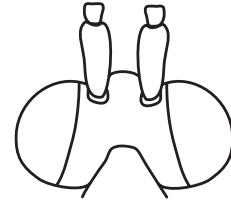

19

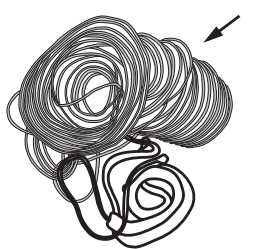

25

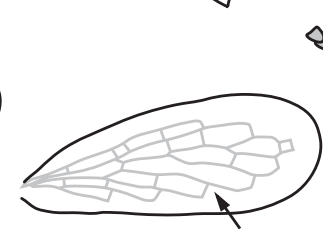

21

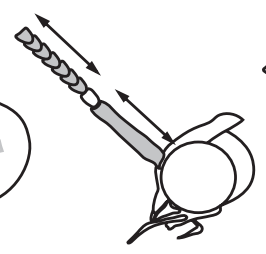

22

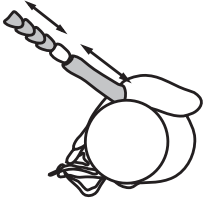

23

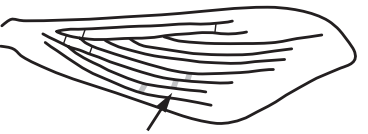

24

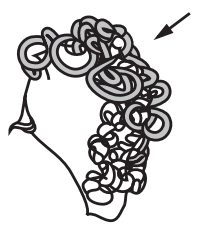

26

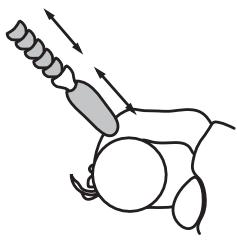

27

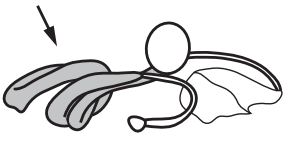

28

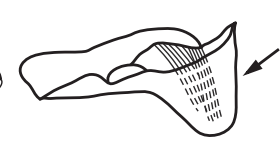

29

Figures 2-29. Schematic drawings with the identifying characteristics in the key. 2. Stenobiella cardaleae $\partial$, fore and hind wing;

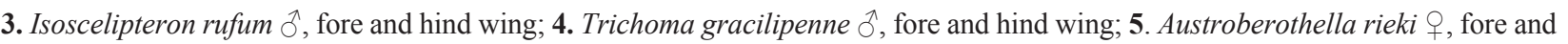

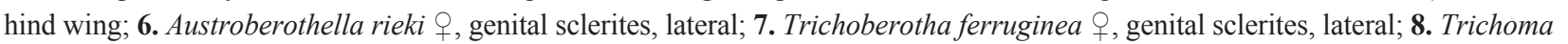
gracilipenne + , genital sclerites, lateral; 9. Spermophorella goobita + , genital sclerites, lateral; 10. Spermophorella sp. + , head and pronotum lateral; 11. Quasispermophorella ingwa ${ }_{+}$, complex of bursa copulatrix and spermatheca; 12. Spermophorella goobita + , complex of bursa copulatrix and spermatheca; 13. Austroberothella rieki $\hat{\partial}$, sternite 9 ventral; 14. Trichoberotha ferruginea $\hat{\partial}$, gonocoxite complex 10; 15. Spermophorella kurtbaueri $\widehat{\partial}$, gonocoxite complex 10; 16. Quasispermophorella ingwa $\widehat{\jmath}$, gonocoxite complex 10; 17. Berotha indica + , fore and hind wing; 18. Lekrugeria koenigi ${ }_{+}$, head dorsal; 19. Nodalla saharica, head dorsal; 20. Nyrma kervillea $\odot$, head frontal; 21. Nyrma kervillea $\widehat{\partial}$, forewing; 22. Podallea vasseana,, , head lateral; 23. Isoscelipteron fulvum,, , head lateral; 24. Asadeteva vartianorum $\widehat{\partial}$, hind wing; 25. Podallea arabica $\uparrow$, complex of bursa copulatrix and spermatheca; 26. Podallea squamulata ${ }^{\lambda}$, gonocoxite complex 10; 27. Berlekrumyia africanella $\partial^{\lambda}$, head lateral; 28. Berlekrumyia africanella ${ }_{+}$, complex of bursa copulatrix and spermatheca; 29. Berlekrumyia africanella $\hat{\partial}$, gonocoxite complex 10. 


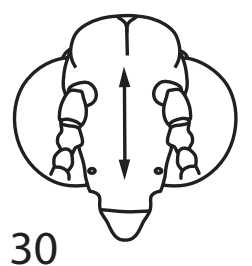

30

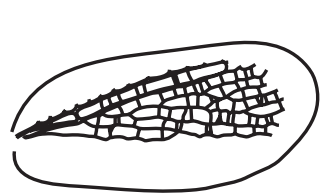

35

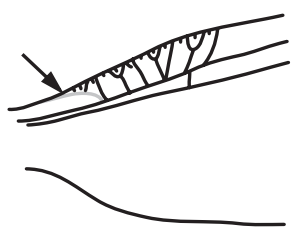

41

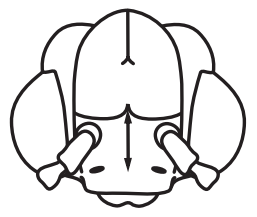

31

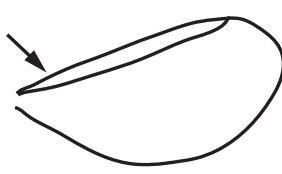

32

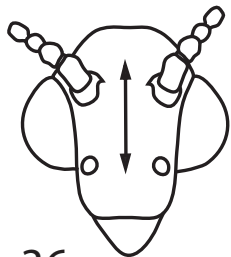

36

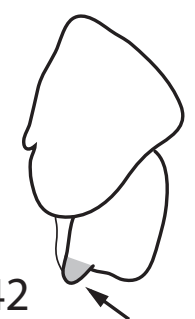

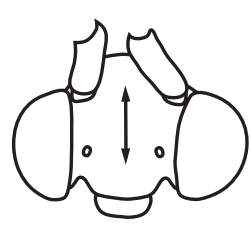

37

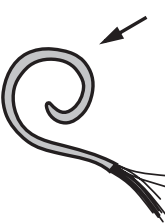

43

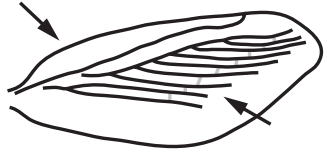

33

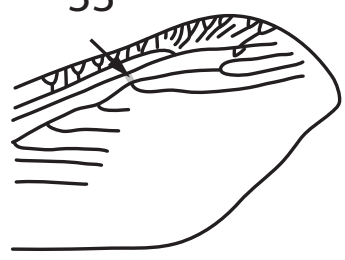

38

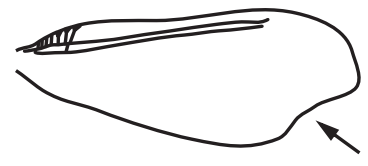

44

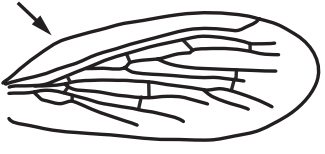

34

Figures 29-46. Schematic drawings with the identifying characteristics in the key. 30. Manselliberotha neuropterologorum $\circ$, head frontal; 31. Nosybus minutus $q$, head frontal; 32. Tanzanberotha hirsuta, ${ }_{0}$, fore wing; 33. Lekrugeria koenigi ${ }_{+}$, fore wing; 34. Nosybus nobilis $\hat{\partial}$, forewing; 35. Ormiscocerus nitidipennis $\hat{\partial}$, forewing; 36. Cyrenoberotha penai, head frontal; 37. Spiroberotha sanctarosae $\hat{~} \hat{\text {, }}$, head frontal; 38. Spiroberotha sanctarosae $q$, forewing; 39. Spiroberotha sanctarosae $q$, genital sclerites, lateral; 40. Spiroberotha sanctarosae $\widehat{\partial}$, gonocoxite complex 10; 41. Naizema mendozina $\hat{\partial}$, forewing; 42. Naizema mendozina + , genital sclerites, lateral; 43. Naizema mendozina $\hat{\partial}$, gonocoxite complex 10; 44. Lomamyia flavicornis, forewing; 45. Lomamyia latipennis + , genital sclerites, lateral; 46. Lomamyia latipennis, $\widehat{\jmath}$, gonocoxite complex 10.

5. Antennal scape, length: at most twice the length of the pedicellus (0), about four times the length of the pedicellus (1), about six times the length of the pedicellus (2), see Aspöck and Nemeschkal (1998; char. 4).

6. Pronotum, transverse furrows: present (0), absent (1), see Aspöck and Nemeschkal (1998; char. 5).

7. Pronotum, number of transverse furrows: one (0), two (1), see Aspöck and Nemeschkal (1998; char. 5).

8. Pronotum, length: about as long as broad (0), shortened (1), elongate (2), see Aspöck and Nemeschkal (1998; chars 6, 7).

9. Thorax, scales: absent (0), present (1), see Aspöck and Nemeschkal (1998; char. 9).

10. Forelegs: cursorial (0), raptorial (1), see Aspöck and Nemeschkal (1998; char. 10).

11. Wings, apex: rounded (0), subfalcate to slightly falcate (1), strongly falcate (2), see Aspöck and Nemeschkal (1998; char. 11).

12. Pterostigmal region: distinct (0), absent (1), see Aspöck and Nemeschkal (1998; char. 13).

13. Forewing, recurrent humeral vein: present (0), absent (1), see Aspöck and Nemeschkal (1998; char. 14).

14. Forewing, stems of $R$ and $M$ : separate to base (0), fused at or before base (1), see Aspöck and Nemeschkal (1998; char. 15).

15. Forewing, vein “ $b$ ", proximal of MP fork: present (0), absent (1), see Aspöck and Nemeschkal (1998; char. 16).
16. Forewing, number of sc-r crossveins: 0-2 (0), 3-5 (1), see Aspöck and Nemeschkal (1998; char. 17).

17. Forewing, number of CuA branches: one (0), two or more (1), see Aspöck and Nemeschkal (1998; char. 18).

18. Forewing, A1 vein, distal branching: with simple dichotomous marginal branching (0), additional marginal branching (1), "creeping" (=pectinate, with only short veinlets along wing margin) (2), no branching (3), see Aspöck and Nemeschkal (1998; char. 19).

19. Hindwing, stems of $R$ and $M$ : free (0), fused at base (1), see Aspöck and Nemeschkal (1998; char. 20).

20. Hindwing, vein " $b$ " (free basal part of $M A)$ : sinuate (0), crossvein-like (1), absent (2), see Aspöck and Nemeschkal (1998; char. 21).

21. Hindwing, base of CuP: present (0), absent (1), see Aspöck and Nemeschkal (1998; char. 22).

22. Hindwing, distal part of CuP: simply forked (0), "creeping" (=pectinate, with only short veinlets along wing margin) (1), absent (2), see Aspöck and Nemeschkal (1998; char. 23).

23. Female: wings, scales: absent (0), present (1), see Aspöck and Nemeschkal (1998; char. 24).

24. Male: tergite 9 and ectoproct: free, not fused (0), fused (1), see Aspöck and Nemeschkal (1998; char. 26).

25. Male: sternite 9, caudal region: unpaired (0), paired (1). 

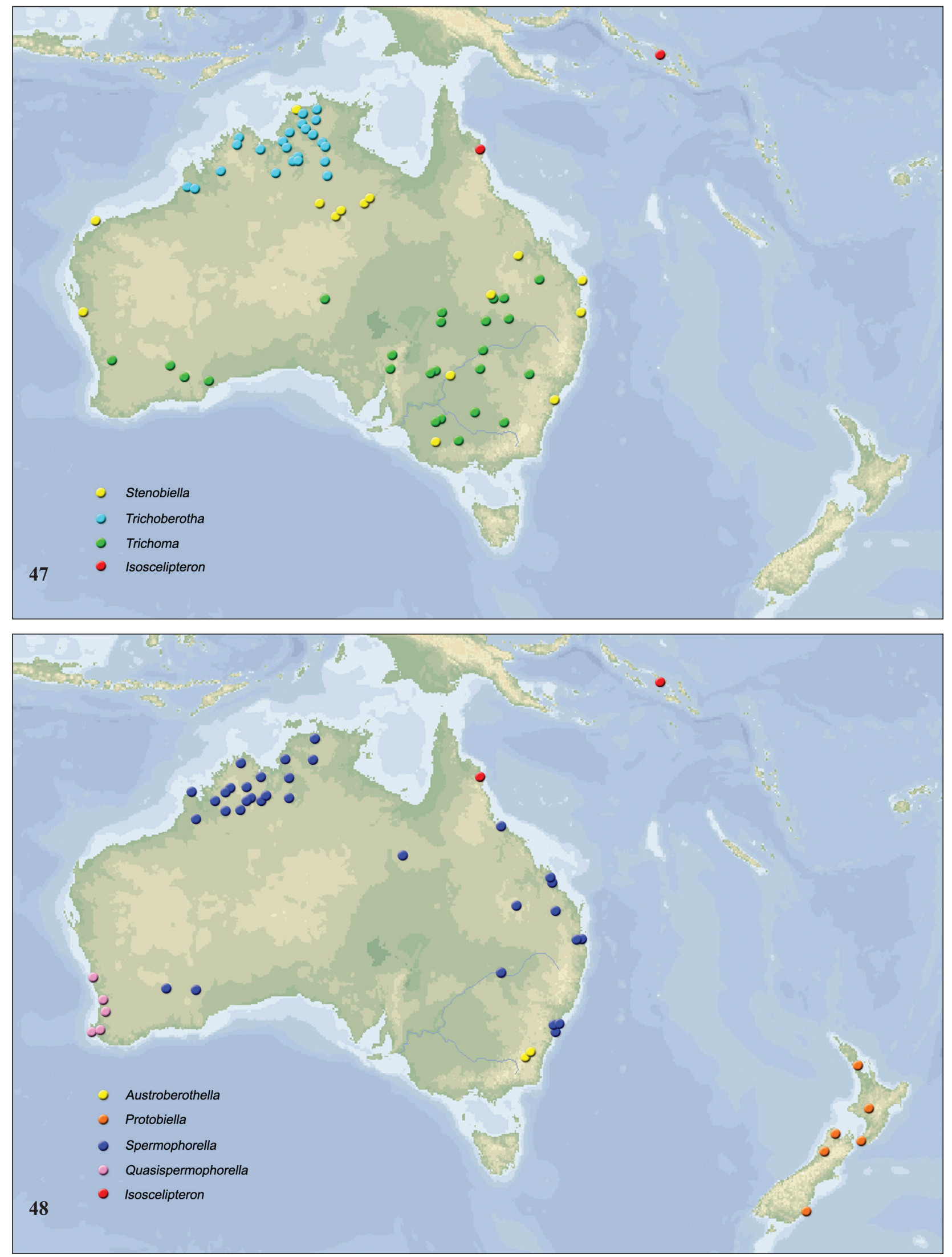

Figures 47-48. Distribution maps of the genera of Berothidae from Australia and New Zealand. 

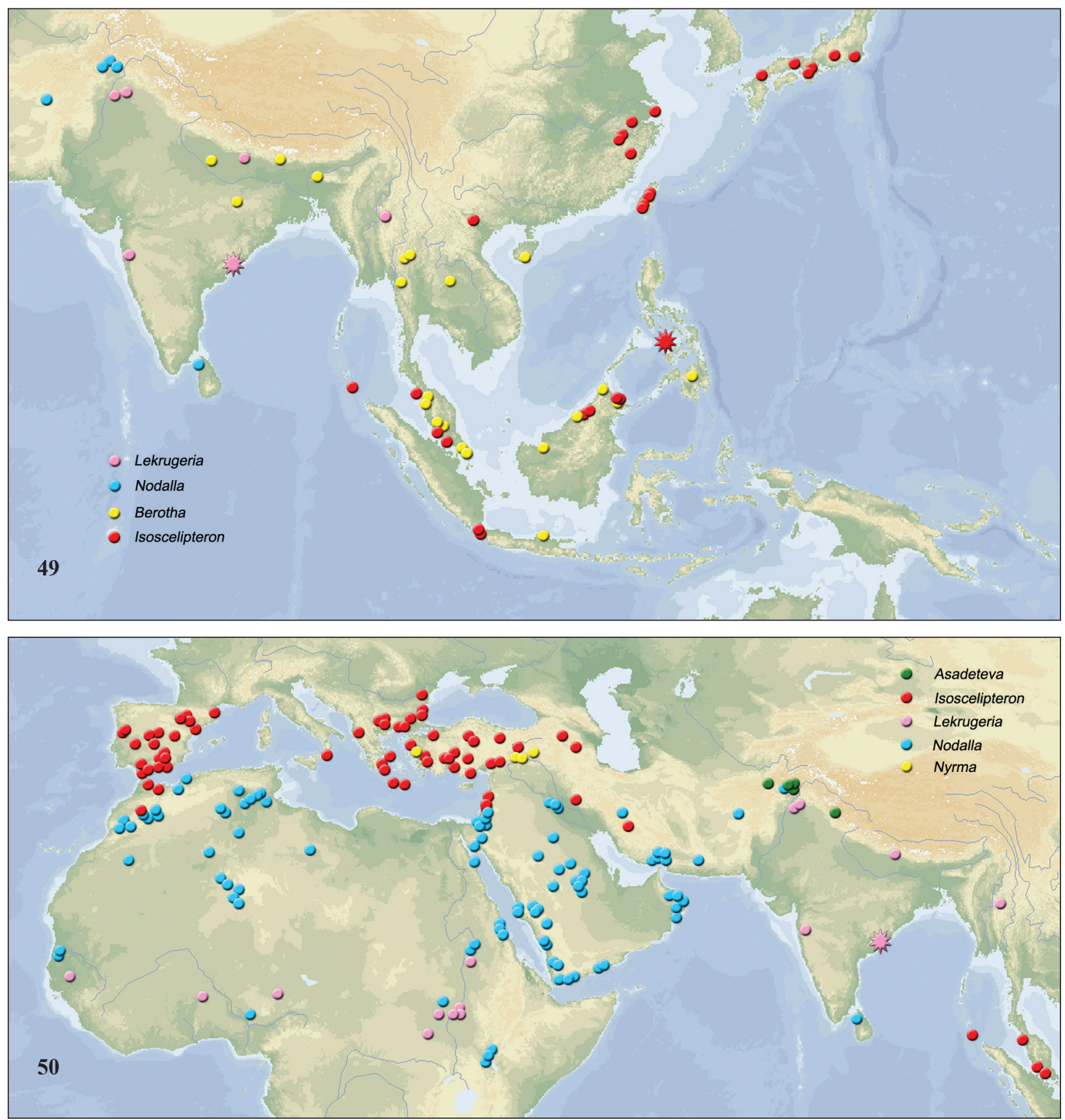

Figures 49-50. Distribution maps of the genera of Berothidae from 49. Oriental and 50. Palaearctic region. Asterisks indicate specimens with imprecise locality.

26. Male: size of sternit 9 compared with sternite 8: of similar lenght (0), reduced (1), enlarged (2), see Aspöck and Nemeschkal (1998; chars 28, 29).

27. Gonocoxit complex 11, dorsocaudal protrusion: absent (0), present (slender) (1), present (prominent) (2), see Aspöck and Nemeschkal (1998; char. 30).

28. Gonocoxit complex 11, fusion with gonocoxites 9: gonocoxite complex 11 associated with gonocoxites 9, but clearly separate (0), gonocoxite complex 11 partially fused with gonocoxites 9 (1), gonocoxite complex 11 amalgamated with gonocoxites 9 (2), gonocoxite complex 11 associated with ectoproct (3), see Aspöck and Nemeschkal (1998; chars 31, 32).
29. Male: ninth gonocoxites, anterior apodeme: absent (0), present (1), see Aspöck and Nemeschkal (1998; char. 33).

30. Gonocoxit complex 10, lateral sclerites: absent (0), present (1), see Aspöck and Nemeschkal (1998; char. 34).

31. Gonocoxit complex 10, bristles: absent (0), present (1), see Aspöck and Nemeschkal (1998; chars 35, 36).

32. Gonocoxit complex 10, length and arrangement of bristles: short and scattered (0), long and bundled (1), see Aspöck and Nemeschkal (1998; chars 36, 37).

33. Gonocoxit complex 10, formations of bristles: simple bow (0), looped (1), thread-like (2), straight (3), see Aspöck and Nemeschkal (1998; chars 38, 39). 


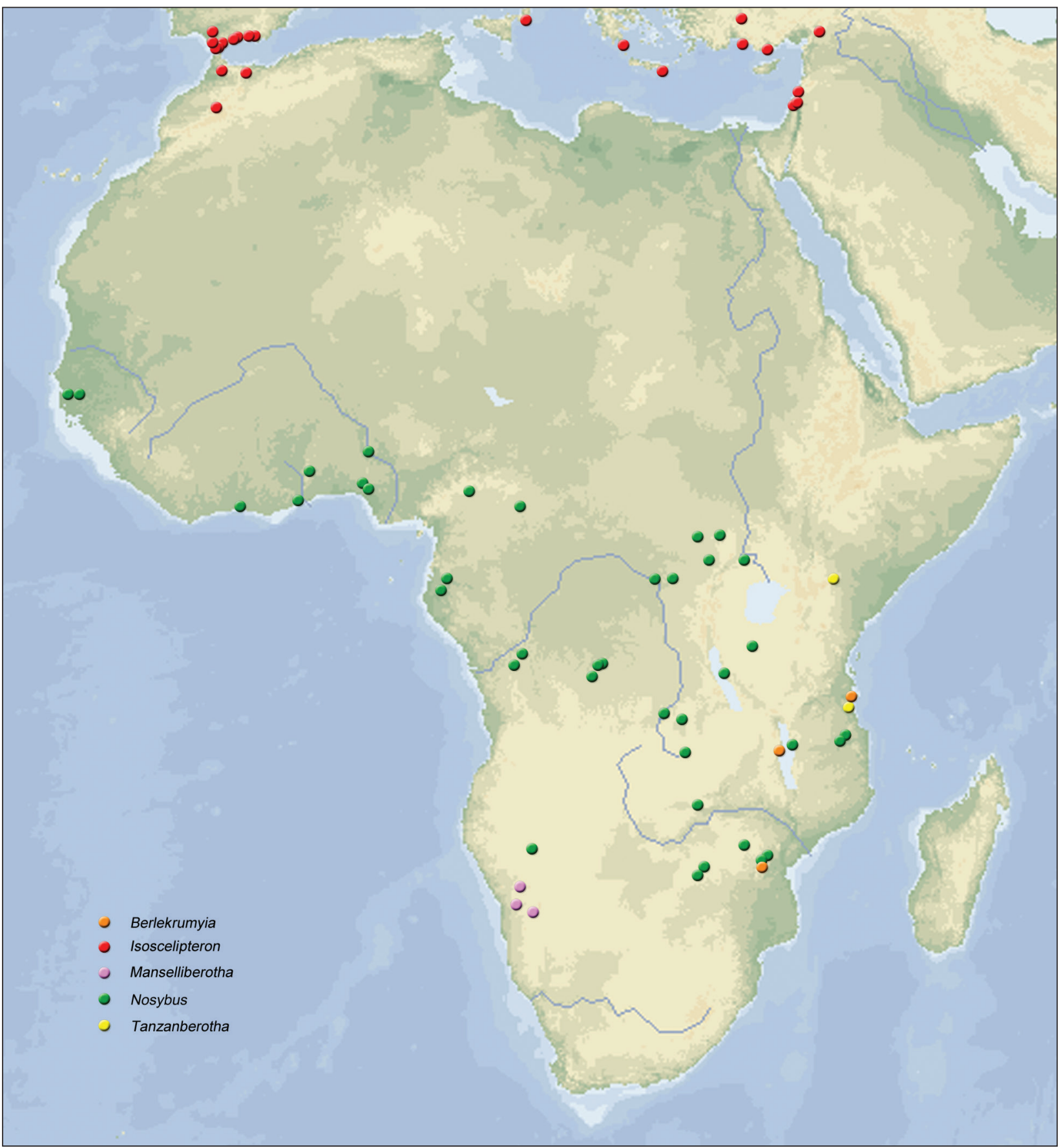

Figure 51. Distribution map of the genera of Berothidae from Afrotropical region and the westernmost records of Isoscelipteron.

34. Torulus (sclerite dorsally above the gonocoxite complex 11): absent (0), present (1), see Aspöck and Nemeschkal (1998; char. 41).

35. Female: tergite 9 and ectoproct: separate (0), fused, see Aspöck and Nemeschkal (1998; char. 42).

36. Female: tergite 9, ventral extremities: continuous with dorsal arch (0), divided from dorsal arch (1), see Aspöck and Nemeschkal (1998; char. 43).

37. Pseudohypocaudae: absent (0), present (1), see Aspöck and Nemeschkal (1998; char. 44).

38. Hypocaudae: absent (0), short (1), long (2), extremely long (3), see Aspöck and Nemeschkal (1998; char. 45).
39. Female: sternite 7: semiannular, posterior margin transverse (0), bilobed, posterior margin distinctly emarginate (1), consisting of a pair of lateral sclerites (gonocoxites 7) (2), see Aspöck and Nemeschkal (1998; char. 46).

40. Female: posterior region of sternum 7 , pair of sclerite disks (gonapophyses 7): absent (0), present (1), see Aspöck and Nemeschkal (1998; char. 47).

41. Female: sternite 8: well developed, reaching tergite 8 laterally (0), reduced, not reaching tergite 8 laterally (1), obliterated (2), see Aspöck and Nemeschkal (1998; char. 48). 


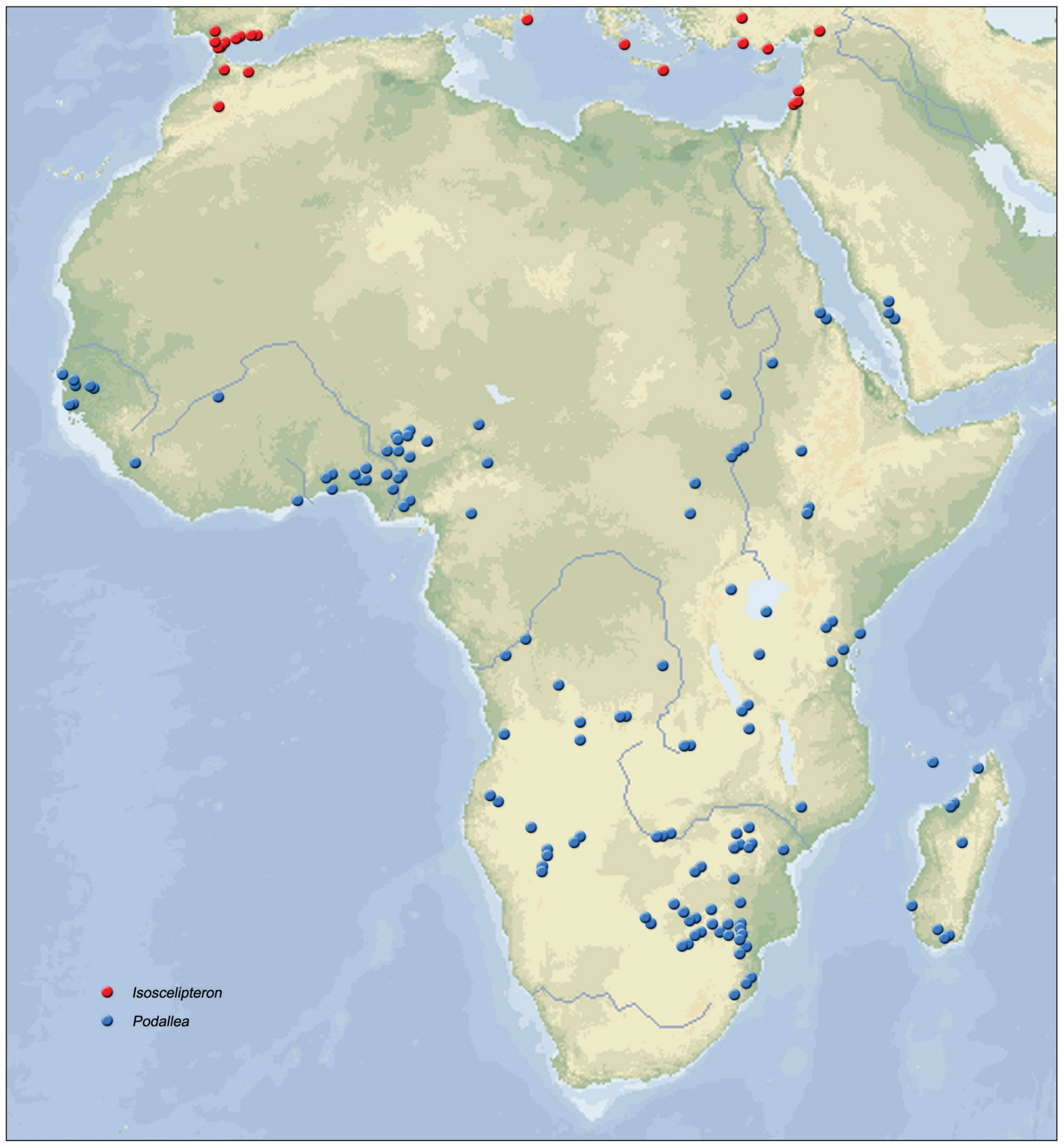

Figure 52. Distribution map of Podallea from Afrotropical region and the westernmost records of Isoscelipteron.

42: Female: sternite 8, ventral processus: absent (0), present, one pair processus (1), present, one median processus (2), see Aspöck and Nemeschkal (1998; char. 49).

43. Pudiculum: absent (0), present, well developed (1), present, reduced (2), see Aspöck and Nemeschkal (1998; char. 50).

44. Bursa copulatrix, size: small (0), large (1), see Aspöck and Nemeschkal (1998; char. 51).

45. Bursa copulatrix, sclerotization: membranous (0), sclerotized (1), see Aspöck and Nemeschkal (1998; char. 51).
46. Receptaculum seminis, globular element: globular (0), elongate (1), see Aspöck and Nemeschkal (1998; char. 52).

47. Ductus receptaculi: short (0), elongate (1), coiled (2), see Aspöck and Nemeschkal (1998; char. 53).

48. Foretarsus, male/female: 5-segmented in male and female (0), 4-segmented in male, 5-segmented in female (1), 4-segmented in male and female (2), see Aspöck and Nemeschkal (1998; char. 55).

49. Long ovipositor: absent (0), present (1), see Aspöck and Nemeschkal (1998; char. 56).

50. Forecoxae of males: not inflated (0), inflated (1). 


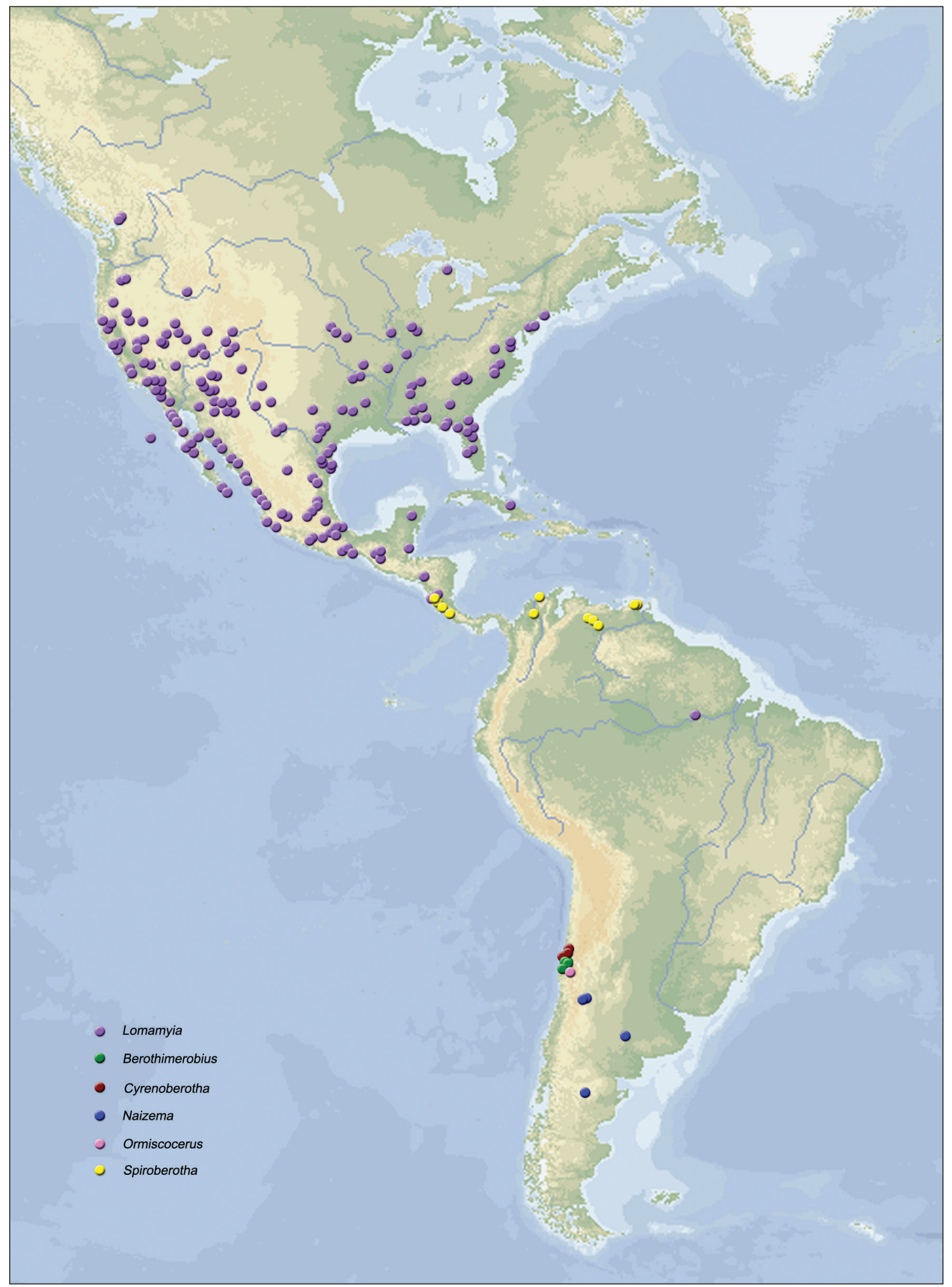

Figure 53. Distribution map of the genera of Berothidae from Nearctic and Neotropical region. 


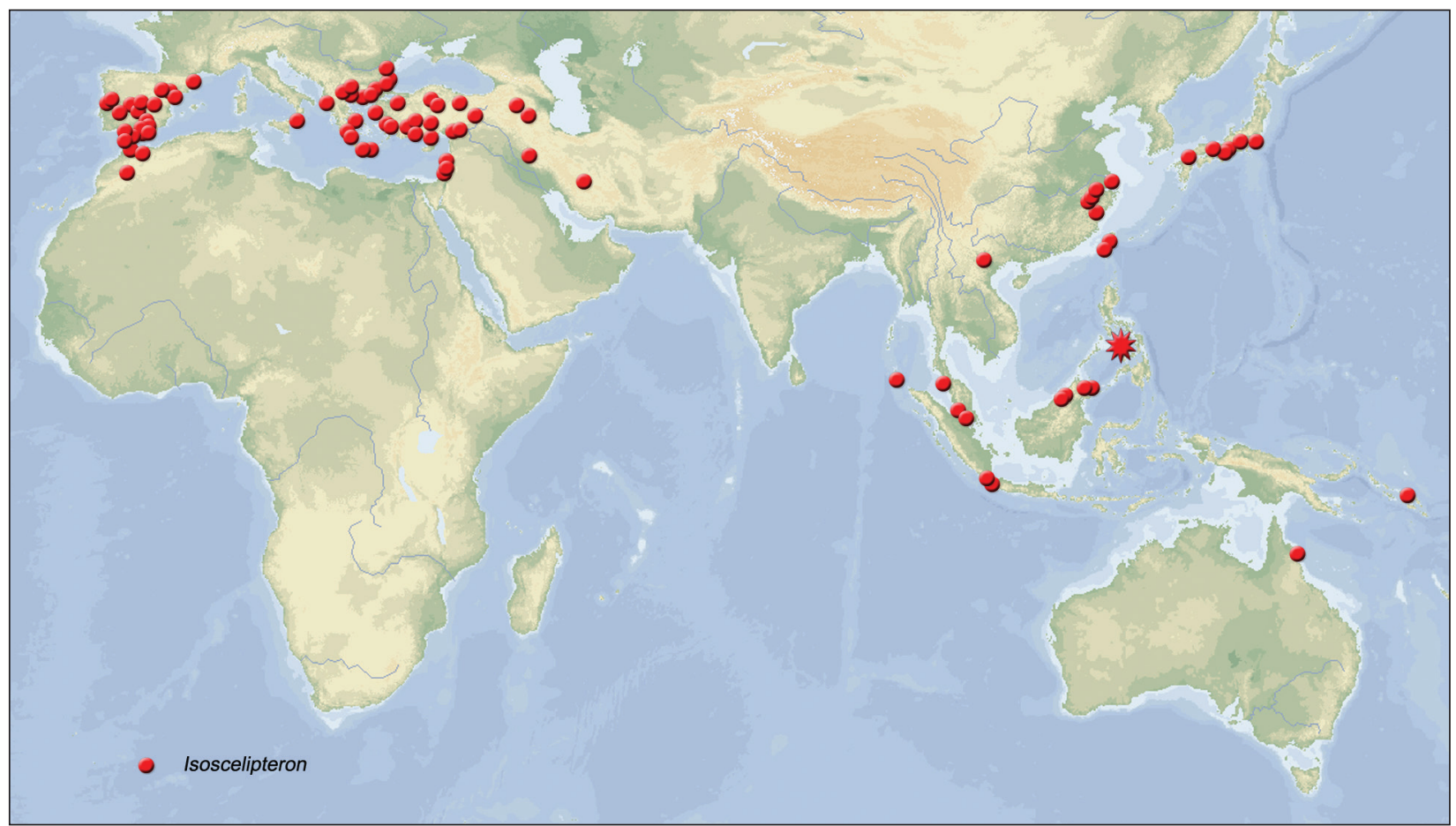

Figure 54. Distribution map of the genus Isoscelipteron worldwide. Asterisk indicates specimen with imprecise locality.

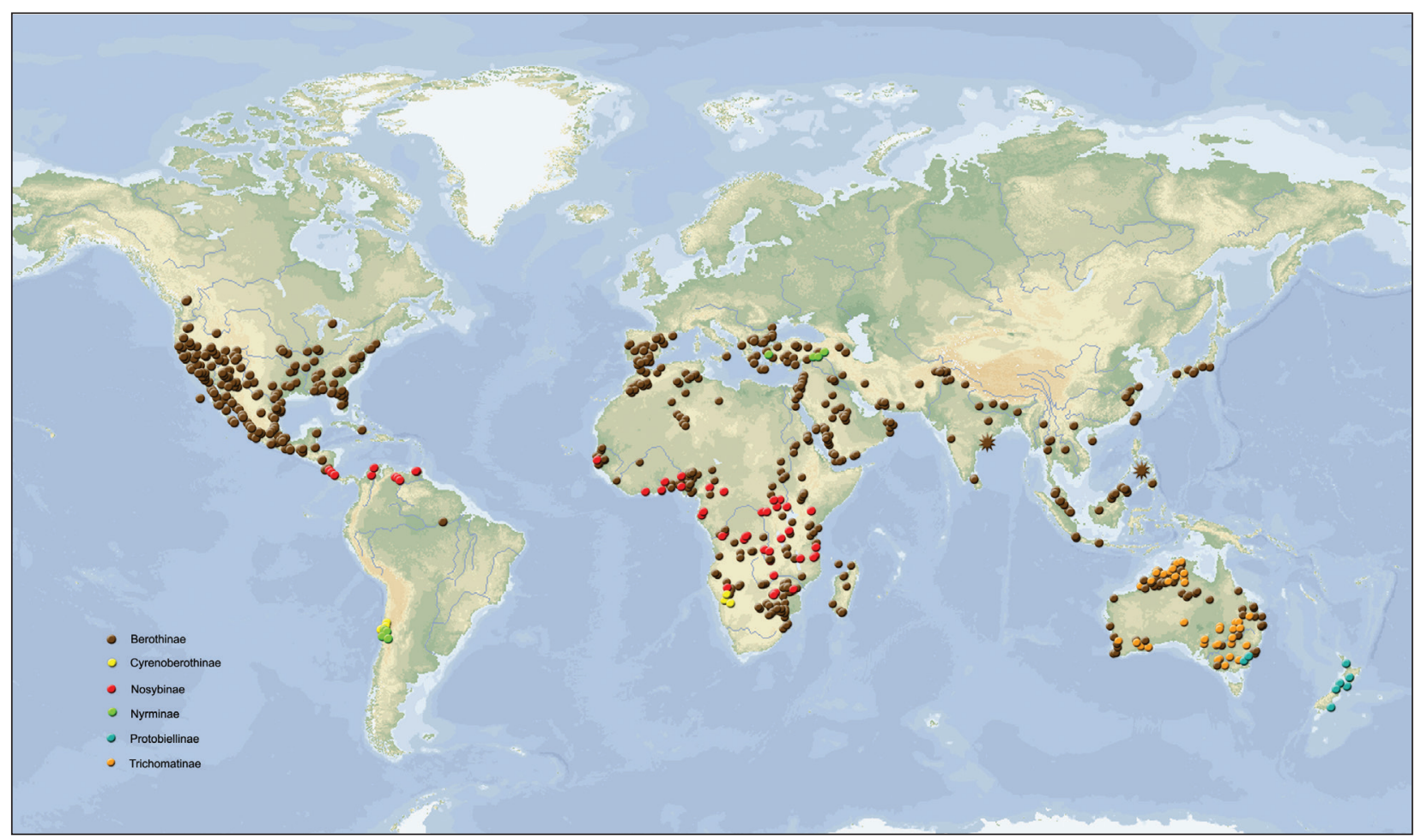

Figure 55. Distribution map of the subfamilies of Berothidae worldwide. Asterisks indicate specimens with imprecise locality.

\section{Cladistic analyses}

The analysis using equal weights yielded twenty most parsimonious trees (MPTs) with a length of 209 steps, a consistency index $(\mathrm{CI})$ of 0.34 , and a retention index (RI) of 0.6. Bremer Support values and Bootstrap values are indicated in Fig. 57. In the MPTs the position of Nyrma is very unstable: it took any possible position within the Nyrminae, and in two trees the genus was sister group to the Cyrenoberothinae. Naizema, belonging to the Nosybinae, consistently resulted as sister group of the Trichomatinae in the MPTs. Spiroberotha, another 
nosybinae genus, switched between a position as sister group of Nosybus + Tanzanberotha within the Nosybinae, and a position as sister group of Naizema + Trichomatinae. Within the Berothinae, Stenobiella switched between being sister to all except Berlekrumyia and sister to all except Berlekrumyia plus the clade (Podallea + (Nodalla + Asadeteva)).

Three different topologies were retrieved by implied weighting with K3-15, none of which represents a MPT. Weighting with K3-4 and K6 yielded a tree that is 212 steps long, as did weighting with K5. These two tree topologies differ only in the position of Stenobiella which is the sister group of Nodalla + Asadeteva under K5, and sister group of a larger clade comprising Nodalla + Asadeteva as well as Podallea and the Isoscelipteron clade. The two tree topologies are consistent in that Podallea is the sister group of the Isoscelipteron clade, and in Trichomatinae being the sister group to Nosybinae + Berothinae. Implied weighting with K7-15 yielded a tree with 210 steps. In that tree, the subfamily Nosybinae was not retrieved as monophyletic since the nosybinae genus Naizema was the sister group of the Trichomatinae as in all MPTs.

\section{Discussion}

\section{Biogeography}

The distribution areas of berothid genera are extremely diverse. At present they cannot be assigned to known general patterns, although they certainly contribute to an understanding of their biogeography.

The Australian region (Figs 47, 48) comprises 8 genera (representing 27 described species), all of them - with only one exception, Isoscelipteron - are endemic. Some have undergone an amazing radiation, e.g. Stenobiella, with 12 described species and more awaiting description. Stenobiella has the largest distribution area, mainly occurring in the eastern half of the continent but with two vicariant species in the west. Trichoberotha, comprising two species, is restricted to northwestern Australia, the vicariant monotypic sister group Trichoma has a much larger distribution area in the southern half of the continent. Quasispermophorella is characterized by vicariant distribution areas of its two species in south-western and south-eastern parts of the continent. Spermophorella comprises six species which are disjunctly distributed along northern, eastern and southern borders of the continent. Isoscelipteron is distributed in the northeast, nested between the disjunct distribution areas of Spermophorella. The origin of the distribution pattern is not yet understood for the monotypic Austroberothella with two species in the southeast of the continent and its monotypic sister group Protobiella from New Zealand.

The Oriental region (Figs 49, 54, 55) comprises four genera with altogether 16 species. The most diverse genus Berotha with altogether five species is endemic to the Oriental region and is scattered over large areas of this realm. The genus Isoscelipteron is recorded with four species from several islands in the Oriental realm and apparently has its main diversification in this region (with only two other species in the Palearctic and one in the Australian region). Lekrugeria occurs in the northwestern transition-zone to the Palearctic region with two species (and another in the Afrotropical region, see below). The record of one species of Nodalla (predominantly distributed in Palearctic Africa, see below) from Sri Lanka might be mislabelled.

The Palaearctic region (Figs 50, 54, 55) comprises five genera representing 15 described species. Nodalla is an element of the Eremic and distributed within the West Palearctic desert belt from northwestern Africa throughout the Arabian Peninsula to Afghanistan. With eleven known species it is the most diverse Palearctic genus (Aspöck and Aspöck 1998). Whether the intra-generic differentiations date back to the Pleistocene or are much older remains speculative at present. Isoscelipteron, which is predominantly known from the Oriental (see above) and Australian regions (one species), is represented by a western-mediterranean and an eastern-mediterranean species. Asadeteva is known from two species in Pakistan and Afghanistan, respectively, both from high altitudes (1400 m $-1800 \mathrm{~m}$ ). The species are certainly Palaearctic elements, however occupy a transition zone to the Oriental realm. The monotypic enigmatic genus Nyrma which is so far only known from Anatolia has a highly disjunct Neotropical sister group (Ormiscocerus + Berothimerobius Fig. 53). This vicariance pattern is not typically Gondwanean and is not yet understood.

The Afrotropical region (Figs 51, 52, 55) comprises six genera, representing 26 species. The most diverse genus Podallea is represented by 15 species. Its distribution is confined to the Afrotropical region, including the southwestern part of the Arabian Peninsula, Madagascar and the Comoro Islands. All Podallea species are arboreal elements. The extant distribution patterns are probably mainly the result of vicariance events apparently long before the Pleistocene (Aspöck and Aspöck 1981, 1996). The five species from Madagascar are closely related or identical with the Podallea species from the African mainland and are certainly the result of not very old colonizations (Aspöck et al. 2010). Nosybus (comprising seven species) and its monotypic sister group Tanzanberotha from Tanzania and Kenya are endemic to the Afrotropical region. Their common Neotropical sister group (Spiroberotha + Naizema) demonstrates a classical Gondwanean vicariance pattern (but see the above mention of the conflict with the Australian Trichomatinae). Lekrugeria comprises one Afrotropical species which is distributed along a sub-Saharan belt and two other species occurring in Northern India and Nepal in a small transition zone of the Palearctic and the Oriental regions. The genus represents a Palaearctic-Subsaharan-Oriental pattern, which is unique among Berothidae (Aspöck and Aspöck 1986 c). The monotypic endemic genus Manselliberotha from southern Africa exemplifies another 
Gondwanean vicariance pattern with its sister group, the Neotropical Cyrenoberotha. The monotypic isolated genus Berlekrumyia which is recorded from southern Africa is endemic to the Afrotropical region.

Berothidae of the Nearctic and Neotropical regions (Figs 53, 55) predominantly occupy the southern parts of NorthAmerica, as well as parts of Central and South America. The most common taxon is Lomamyia, vicariant to all other Berothinae which are restricted to other continents. The genus comprises 12 species, 10 in North America, one in Central America and one in eastern South America. All other genera of this region represent relic taxa, with one or two species only; however, they are characterized by vicariant sister groups in the Old World. The monotypic genera Ormiscocerus and Berothimerobi$u s$ are endemic to Chile. The transoceanic vicariance with their joint sister group Nyrma from Anatolia does not fit into any of the typical Gondwanean patterns. The monotypic relic genus Cyrenoberotha is endemic to Chile, representing the Neotropical counterpart to Manselliberotha from the Afrotropical region. It may be interpreted as a typical Gondwanean pattern - however, its origin is not yet understood. Spiroberotha (two species) from Central America and northern South America and the vicariant Naizema (two closely related species or monotypic) from southern South America represent an unknown pattern (both belonging to the otherwise Afrotropical Nosybinae).

In summary, it can be stated that the distribution patterns of berothid genera are extremely heterogeneous. Their origin, biogeographic and biological backgrounds and their congruence with general patterns are far from being understood.

1) Two types of Gondwanean patterns are distinguishable: Neotropical / Afrotropical vicariance on the one hand, represented e.g. by Cyrenoberotha / Manselliberotha (Figs 51, 53), and Afrotropical / Australian vicariance and on the other hand, e.g. represented by Podallea (Fig. 52) and the Isoscelipteron clade (Fig. 47).

2) One genus, Lekrugeria, marks a sub-Saharan $\mathrm{Pa}$ laearctic belt which extends to the Palaearctic/Oriental transgression zone (Fig. 50).

3) The genus with the largest and highly vicariant distribution area, Isoscelipteron, comprises the Palearctic, Oriental and Australian regions (Fig. 54).

4) Finally: Endemism is a very common phenomenon among Berothidae, with radiations of genera within biogeographic realms, on one hand, or as monotypic enigmatic locus typicus relics, on the other hand.

\section{Phylogeny}

The results of our cladistic analyses will be discussed in the context of previous results reported in Aspöck and Nemeschkal (1998), on one hand, and concerning their plausibility, on the other hand. Prima vista it can be emphasized that the Rhachiberothidae (Figs 56, 57: Mucroberotha + Rhachiberotha), which in the present analysis was part of the out-group, is corroborated as a discrete family, which has already been advertised by Aspöck and Mansell (1994). This contrasts with the interpretation of the rhachiberothids as a subfamily of the Berothidae which was originally proposed by Tjeder (1959) and more recently advocated by Winterton et al. (2010).

Generally, it is noteworthy that the trees retrieved with strong implied weighting (K3-6) are mostly congruent with the previous analysis by Aspöck and Nemenschkal (1998), while major conflicts emerge in the MPTs and the trees with implied weighting above K7. Conflicts in the shorter trees (MPTs and $\mathrm{K} 7+$ ) concern the Trichomatinae (Fig. 56: TRI) appearing as part of the Nosybinae (Fig. 56: NOS) and the position of the genus Podallea as sister to Nodalla + Asadeteva within the Berothinae (Fig. 56: BER).

Within the Nosybinae the genus Nosybus (comprising seven species) and the monotypic Tanzanberotha, both from the Afrotropics (Fig. 51), emerged as the sister group of Spiroberotha (two species) from the Neotropical region (Fig. 53). These three genera are the sister group of the Neotropical Naizema (two species). Yet, the Trichomatinae appear as sister group of Naizema and thus within the Nosybinae in all shorter trees. However, this result lacks plausibility, since the complex of the gonocoxites 10 in the Nosybinae is highly differentiated, enlarged and rolled up, whereas in the Trichomatinae the complex is simple. In Aspöck and Nemeschkal (1998) and in the trees obtained by implied weighting with K3-6, the Trichomatinae are the sister group of Nosybinae + Berothinae. The Trichomatinae are endemic in the Australian region (Fig. 47) and comprise two genera: the monotypic Trichoma and Trichoberotha (with two species).

The Berothinae represent the largest clade of Berothidae and emerged as a monophylum in all trees (Figs 56, 57). They comprise 11 genera: Asadeteva (two species from Asia, Fig. 50), Nodalla (11 species from northern Africa, Fig. 50), Stenobiella (12 species endemic to Australia, Fig. 47), Berotha (five species, Oriental region, Fig. 49), Lekrugeria (three species, Subsahara and Asia, Fig. 49, 50), and Lomamyia (12 species, Neactic and Neotropical region, Fig. 53). The monotypic Afrotropical Berlekrumyia appears as the sister group to the rest in all MPTs, as in Aspöck and Nemeschkal (1998), but not in the trees obtained by implied weighting with K3-6, where Lomamyia holds this position. The Podallea clade comprises the Afrotropical Podallea (with 15 species), the Isoscelipteron clade with Isoscelipteron (Palaearctic, Oriental and Australian regions with 13 species) and Quasispermophorella (two species) + Spermophorella (six species) with the latter two genera being endemic to the Australian region (Fig. 48). The monophyly of the Podallea clade was one of the highlights in the study by Aspöck and Nemeschkal (1998) and was a most convincing result. In the present analysis this relationship was obtained by implied weighting with K 3-6. However, it is most surprising and lacks plausibility that in the MPTs and under implied weighting with K7-15 (compare strict consensus Fig. 57), Podallea emerged consitsently as 


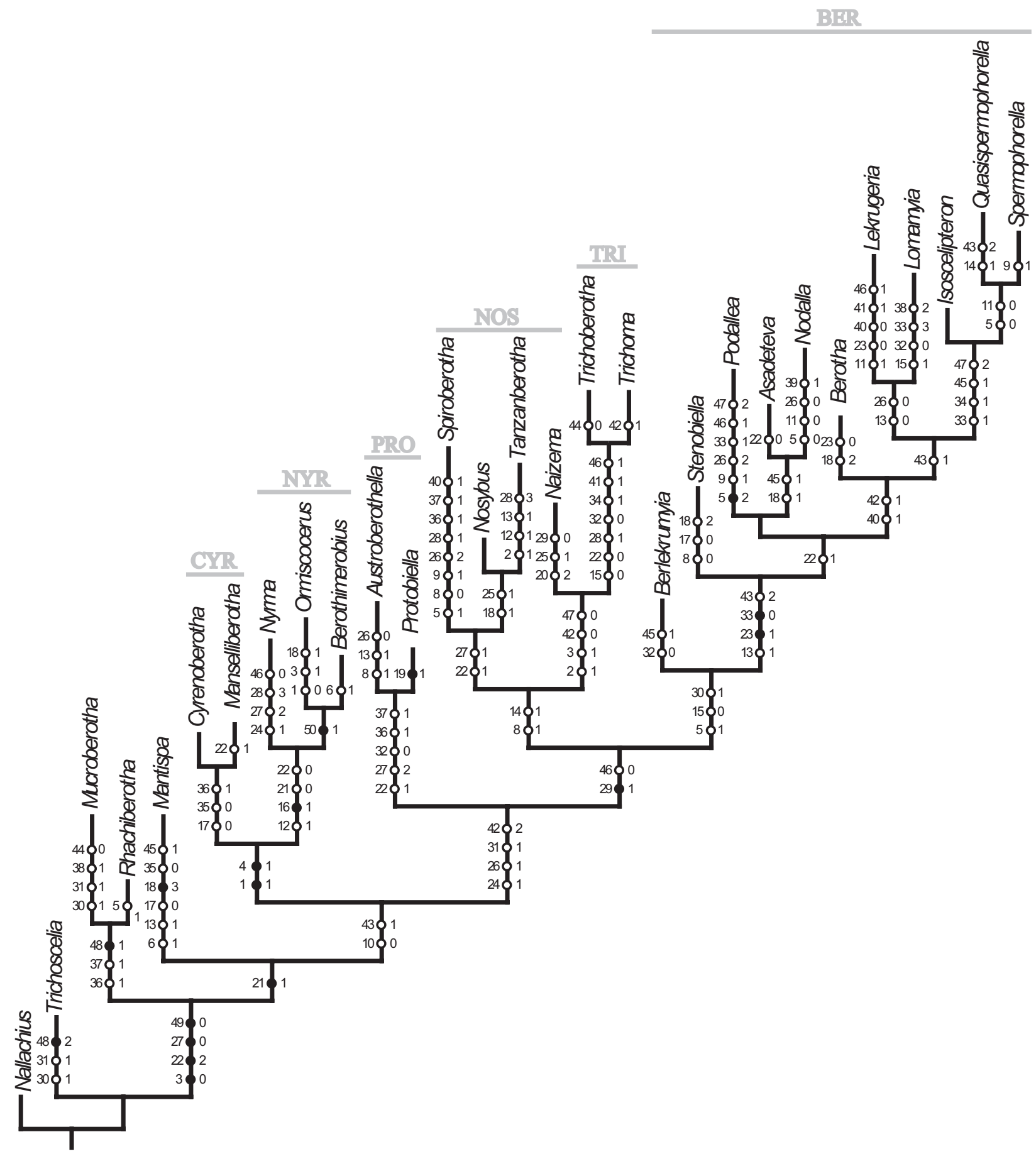

Figure 56. Preferred tree of 20 most parsimonious trees produced by exhaustive search under equal weights with unambiguous character optimization (209 steps, $\mathrm{CI}=0.34, \mathrm{RI}=0.6$ ). Black circles indicate unique synapomorphies, white circles homoplastic ones. BER - Berothinae, CYR - Cyrenoberothinae, NOS - Nosybinae, NYR - Nyrminae, PRO - Protobiellinae, TRI - Trichomatinae.

the sister group of Asadeteva + Nodalla. The characters 33.1 (male: complex of gonocoxites 10 looped) and 47.2 (female: ductus receptaculi coiled), which in our understanding are clearly synapomorphies of Podallea and the Isoscelipteron clade, occur as homoplasies in those trees.

One character complex that is highly interesting in the context of Berothinae and Nosybinae phylogeny is a conspicuous formation of the female sternal region of the abdominal segment seven (chars. 39 and 40): Hairy domed lateral sclerites, interpreted as gonocoxites seven, accompanied by smooth and weakly sclerotized discs which are interpreted as gonapophyses seven (Aspöck and Aspöck 2008). It is present in the Nosybinae genus Spiroberotha and in several genera of Berothinae (Lomamyia, Berotha, Podallea, Isoscelipteron, Quasispermophorella and Spermophorella) and is unique among Berothidae. Due to the peculiarity of the structures, an independent development is rather unlikely. Thus the 


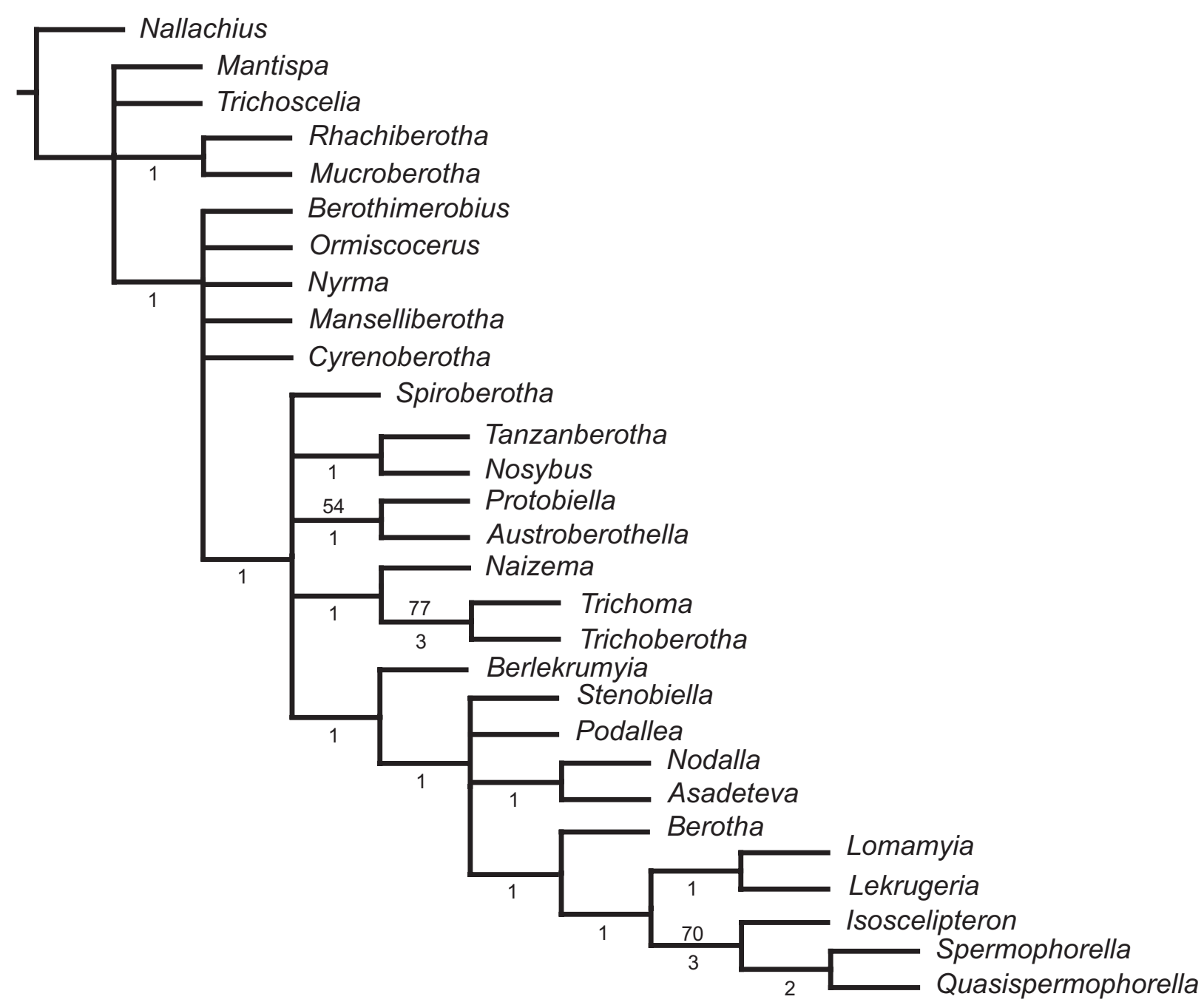

Figure 57. Strict consensus tree produced by exhaustive search under equal weights with bootstrap values over $50 \%$ (above) and Bremer support values (below).

question remains whether it is in fact a synapomorphy of Nosybinae + Berothinae with secondary reductions in some genera, or whether Spiroberotha, a genus which also switches positions in the present analysis, might belong to the Berothinae. The condition of the seventh female abdominal segment is a phenomenon restricted to this subfamily. In a larger context it rises the question whether this differentiation of the seventh sternite is a re-expression tracing back to the combined nature of the abdominal sternites (Aspöck and Aspöck 2008).

The Nyrminae (Fig. 55, Fig. 56: NYR) comprise the hitherto monotypic Nyrma from Anatolia (Fig. 50) and Ormiscocerus + Berothimerobius, both monotypic genera from Chile (Fig. 53). All three genera are apparently old relics from Gondwana (although they do not show a typical Gondwanean vicariance pattern). Character 16.1 (more than three sc-r crossveins in the forewing) is a synapomorphy of Nyrma, Ormiscocerus and Berothimerobius (Fig. 56). The inflated forecoxae of the males (char. 50.1) of Ormiscocerus and Berothimerobius are a very striking synapomorphy of the two genera (Fig. 56) which are geographically very close together (Fig. 53).

\section{Concluding remarks}

The discussion of the distribution areas of the genera on a worldwide scale serves as a brain storming excerise for a forthcoming biogeographic analysis which would be premature at the present state of berothid phylogeny. Nevertheless, we expect a positive cybernetic aspect in presenting both approaches. That our phylogenetic tree should be understood as starting point for falsification does not need to be emphasized.

\section{Acknowlegements}

We greatfully acknowledge Harald Bruckner (NHMV) and Franziska Denner (NHMV) for the data acquisition and Harald Bruckner additionally for the drawings of the distribution maps, Dominique Zimmermann (NHMV) for her help with tricky TNT problems, Wolfgang Brunnbauer (NHMV) for acquisition of literature, Horst Aspöck (Medical University of Vienna) for permanent discussion on berothids and valuable comments on the manuscript, and John Plant for linguistic improvements and critically reading 
the manuscript. We want to thank the two reviewers for their essential input and the Museum für Naturkunde Berlin for publishing this article in open access and free of charge.

\section{References}

(Including references for the templates of Figs 2-46)

Adams P A (1989) A new genus of Berothidae from tropical America, with two new species. Psyche 96: 187-193. doi: 10.1155/1989/39647

Ardila-Camacho A (2013) First record of Beaded Lacewings (Neuroptera, Berothidae) from Colombia. Zootaxa 3669(2): 159-164. doi: 10.11646/Zootaxa.3669.2.7

Aspöck U (1983) Das Genus Berotha Walker (Neuropteroidea: Planipennia: Berothidae). Annalen des Naturhistorischen Museums in Wien 84B: 463-478.

Aspöck U. (1986) The present state of knowledge of the family Berothidae (Neuropteroidea: Planipennia). In: Gepp J, Aspöck H, Hölzel H (Eds) Recent Research in Neuropterology. Proceedings of the $2^{\text {nd }}$ International Symposium on Neuropterology. Privately printed, Graz, Austria, 87-101.

Aspöck U (1989) Nyrma kervillea Navás - eine Berothide! (Neuropteroidea: Planipennia). Zeitschrift der Arbeitsgemeinschaft Österreichischer Entomologen 41: 19-24.

Aspöck U, Aspöck H (1979) Nyrma kervillea Navás - Wiederentdeckung einer systematisch isolierten Hemerobiiden-Spezies in Kleinasien. Zeitschrift der Arbeitsgemeinschaft Österreichischer Entomologen 31: 92-96.

Aspöck U, Aspöck H (1981a) Das Genus Podallea Navás, 1936 (Neuropteroidea: Planipennia: Berothidae). Zeitschrift der Arbeitsgemeinschaft Österreichischer Entomologen 32: 81-96.

Aspöck U, Aspöck H (1981b) Weitere Untersuchungen an Berothiden: Berotha Walker, Isoscelipteron Costa und Asadeteva n. g. (Neuropteroidea: Planipennia). Zeitschrift der Arbeitsgemeinschaft Österreichischer Entomologen 33: 1-14.

Aspöck U, Aspöck H (1984) Die Berothiden Australiens I: Neue Spezies des Genus Stenobiella Tillyard (Neuropteroidea: Planipennia: Berothidae). Zeitschrift der Arbeitsgemeinschaft Österreichischer Entomologen 36: 17-32.

Aspöck U, Aspöck H (1985) Die Berothiden Australiens (und Neuseelands) II: Die Genera Trichoma Tillyard, Trichoberotha Handschin, Protobiella Tillyard und Austroberothella n. g. (Neuropteroidea: Planipennia: Berothidae). Zeitschrift der Arbeitsgemeinschaft Österreichischer Entomologen 36: 65-85.

Aspöck U, Aspöck H (1986a) Die Berothiden Australiens III: Die Genera Spermophorella Tillyard und Quasispermophorella $\mathrm{n}$. g. (Neuropteroidea: Planipennia: Berothidae). Zeitschrift der Arbeitsgemeinschaft Österreichischer Entomologen 38: 17-34.

Aspöck U, Aspöck H (1986b) Die Berothiden Australiens IV: Weitere Untersuchungen über das Genus Spermophorella Tillyard (Neuropteroidea: Planipennia: Berothidae). Zeitschrift der Arbeitsgemeinschaft Österreichischer Entomologen 38: 89-102.

Aspöck U, Aspöck H (1986c) Das Genus Lekrugeria Navás (Neuropteroidea: Planipennia: Berothidae: Berothinae). Zeitschrift der Arbeitsgemeinschaft Österreichischer Entomologen 37: 85-98.

Aspöck U, Aspöck H (1988a) Berlekrumyia africanella n. g. et n. sp. und Podallea manselli n. sp. - zwei neue Berothiden-Spezies aus Südosten
Afrikas (Neuropteroidea: Planipennia: Berothidae). Zeitschrift der Arbeitsgemeinschaft Österreichischer Entomologen 39: 113-123.

Aspöck U, Aspöck H (1988b) Die Subfamilie Cyrenoberothinae - ein Gondwana-Element? Manselliberotha neuropterologorum n. g. et n. sp. aus S.W.A./Namibia (Neuropteroidea: Planipennia: Berothidae). Zeitschrift der Arbeitsgemeinschaft Österreichischer Entomologen 40: 1-13.

Aspöck U, Aspöck H (1988c) Die Berothiden Australiens V: Zur Systematischen Stellung von Austroberothella rieki U. A. and H. A. (Mit einem kurzen Überblick über die Erforschung der Berothidae Australiens) (Neuropteroidea: Planipennia). Stapfia 17: 135-146.

Aspöck U, Aspöck H (1996) Revision des Genus Podallea Navás, 1936 (Neuroptera: Berothidae: Berothinae). Mitteilungen der Münchner Entomologischen Gesellschaft 86: 99-144.

Aspöck U, Aspöck H (2008) Phylogenetic relevance of the genital sclerites of Neuropterida (Insecta: Holometabola). Systematic Entomology 33: 97-127. doi: 10.1111/j.1365-3113.2007.00396.x

Aspöck U, Hynd WRB (1995) A new genus and species of Nosybinae (Neuropt., Berothidae) from eastern Africa. Entomologist's Monthly Magazine 131: 107-113.

Aspöck U, Liu X, Aspöck H (2013) The Berothidae of Taiwan (Neuroptera: Neuropterida). Deutsche Entomologische Zeitschrift 60(2): 221-230.

Aspöck U, Mansell MW (1994) A revision of the family Rhachiberothidae Tjeder, 1959, stat. n. (Neuroptera). Systematic Entomology 19: 181-206. doi: 10.1111/j.1365-3113.1994.tb00587.x

Aspöck U, Nemeschkal HL (1998) A cladistic analysis of the Berothidae (Neuroptera). In: Panelius SP (Ed.) Neuropterology 1997. Proceedings of the $6^{\text {th }}$ International Symposium on Neuropterology (13-16 July 1997, Helsinki, Finland). Acta Zoologica Fennica 209: 45-63.

Aspöck U, Plant JD, Nemeschkal HL (2001) Cladistic analysis of Neuroptera and their systematic position within Neuropterida (Insecta: Holometabola: Neuropterida: Neuroptera). Systematic Entomology 26: 73-86. doi: 10.1046/j.1365-3113.2001.00136.x

Aspöck U, Randolf S, Aspöck H (2010) The Berothidae of Madagascar (Neuropterida: Neuroptera) and Madagascar's biological exploration by the Viennese adventuress Ida Pfeiffer $(1797$ - 1858). In: Devetak D, Lipovssek S, Arnett AS (Eds) Proceedings of the Tenth Symposium on Neuropterology, Piran, Slovenia, 2008, Maribor Slovenia, 75-82.

Beutel RG, Friedrich F, Aspöck U (2010) The larval head of Nevrorthidae and the phylogeny of Neuroptera (Insecta). Zoological Journal of the Linnean Society 158: 533-562. doi: 10.1111/j.10963642.2009.00560.x

Brushwein JR (1987) Bionomics of Lomamyia hamata (Neuroptera: Berothidae). Annals of the Entomological Society of America 80: 671-679.

Carpenter FM (1940) A revision of the Nearctic Hemerobiidae, Berothidae, Sisyridae, Polystoechotidae and Dilaridae (Neuroptera). Proceedings of the American Academy of Arts and Sciences 74: 193-280. doi: $10.2307 / 20023398$

Dobosz R, Górski G (2008) New data on Nyrma kervilea (Neuroptera: Berothidae). In: Devetak D, Klenovšek T (Eds) Tenth International Symposium on Neuropterology, 22-25 June 2008, Piran, Slovenia. Abstract book. Faculty of Natural Sciences and Mathematics, Maribor, 33.

Engel MS, Grimaldi DA (2008) Diverse Neuropterida in Cretaceous amber, with particular reference to the paleofauna of Myanmar (Insecta). Nova Supplementa Entomologica 20: 1-86. 
Faulkner D K (1992) A revision of the genus Lomamyia Banks (Planipennia: Berothidae) with an emphasis on the western United States species. Master's thesis. California State University, Long Beach, California, 119 pp.

Goloboff PA (1993) Estimating character weights during tree search. Cladistics 9: 83-91. doi: 10.1111/j.1096-0031.1993.tb00209.x

Goloboff PA, Farris JS, Nixon KC (2008) TNT, a free program for phylogenetic analysis. Cladistics 24: 774-786. doi: 10.1111/j.10960031.2008.00217.x

Grimaldi DA (2000) A diverse fauna of Neuropterodea in amber from the Cretaceous of New Jersey. In: Grimaldi DA (Ed.) Studies on Fossil in Amber, with Particular Reference to the Cretaceous of New Jersey. Backhuys Publishers, Leiden, 259-303.

Grimaldi D, Engel MS (2005) Evolution of the Insects. Cambridge University Press, New York, 755 pp.

Gurney AB (1947) Notes on Dilaridae and Berothidae, with special reference to the immature stages of the Nearctic genera (Neuroptera). Psyche 54: 145-169. doi: 10.1155/1947/78317

Haring E, Aspöck U (2004) Phylogeny of the Neuropterida: a first molecular approach. Systematic Entomology 29: 415-430. doi: 10.1111/j.0307-6970.2004.00263.x

Klimaszewski J, Kevan DKMcE (1986) A new lacewing-fly (Neuroptera: Planipennia) from Canadian Cretaceous Amber, with an analysis of its fore wing characters. Entomological News 97: 124-132.

Komatsu T (2014) Larvae of the Japanese termitophilous predator Isoscelipteron okamotonis (Neuroptera, Berothidae) use their mandibles and silk web to prey on termites. Insectes Sociaux 61(2): 203-205. doi: 10.1007/s00040-014-0346-6

Krüger L (1923) Neuroptera succinica baltica. Die im baltischen Bernstein eingeschlossenen Neuroptera des Westpreussischen Provinzial-Museums (heute Museum für Naturkunde und Vorgeschichte) in Danzig. Stettiner Entomologische Zeitung 84: 68-92.

MacLeod EG, Adams PA (1967) A review of the taxonomy and morphology of the Berothidae, with the description of a new subfamily from Chile (Neuroptera). Psyche 74: 237-265.

Makarkin VN, Yang Q, Ren D (2011) Two new species of Sinosmylites Hong (Neuroptera, Berothidae) from the Middle Jurassic of China, with notes on Mesoberothidae. ZooKeys 130: 199-215. doi: 10.3897/zookeys.130.1418

Minter LR (1990) A comparison of the eggs and first-instar larvae of Mucroberotha vesicaria Tjeder with those of other species in the families Berothidae and Mantispidae (Insecta: Neuroptera). In: Mansell MW, Aspöck H (Eds) Advances in Neuropterology. Proceedings of the Third International Symposium on Neuropterology. South African Department of Agricultural Development, Pretoria, 115-129.

Möller A (2003) Aspects of the larval morphology and biology of South African Podallea species (Neuropterida: Neuroptera: Berothidae). Master of Science Thesis. School of Molecular and Life Sciences in the Faculty of Sciences, Health and Agriculture, University of the North, South Africa, 123 pp.

Möller A, Minter LR, Olivier PAS (2006) Larval morphology of Podallea vasseana Navás and Podallea manselli Aspöck and Aspöck from South Africa (Neuroptera: Berothidae). African Entomology 14: 1-12.

Monserrat VJ (2006) Nuevos datos sobre algunas especies de la familia Berothidae (Insecta: Neuroptera). Heteropterus Revista de Entomología 6: 173-207.

Monserrat VJ, Deretsky Z (1999) New faunistical, taxonomic and systematic data on brown lacewings (Neuroptera: Hemerobiidae). Journal of Neuropterology 2: 45-66.
New TR (1986) A review of the biology of Neuroptera Planipennia. Neuroptera International (Supplemental Series) 1: 1-57.

Nixon KC (2002) WinClada. Ver. 1.00.08. Cornell University, Ithaca, NY.

Oswald JD, Contreras-Ramos A, Penny ND (2002) Neuroptera (Neuropterida). In: Bousquets JL, Morrone JJ (Eds) Biodiversidad, Taxonomía y Biogeografía de Artrópodos de México: hacia una síntesis de su conocimiento. Vol. 3. Universidad Nacional Autónoma de México, Distrito Federal, 559-581.

Penny ND, Adams PA, Stange L A (1997) Species catalog of the Neuroptera, Megaloptera, and Raphidioptera of America North of Mexico. Proceedings of the California Academy of Sciences 50(3): 39-114.

Penny ND, Winterton SL (2007) Rediscovery of the unusual genus Ormiscocerus (Neuroptera: Berothidae: Cyrenoberothinae). Proceedings of the California Academy of Sciences (4)58: 1-6.

Randolf S, Zimmermann D, Aspöck U (2013) Head anatomy of adult Sisyra terminalis (Insecta: Neuroptera: Sisyridae) - functional adaptations and phylogenetic implications. Arthropod Structure and Development 42: 565-582. doi: 10.1016/j.asd.2013.07.004

Randolf S, Zimmermann D, Aspöck U (2014) Head anatomy of adult Nevrorthus apatelios and basal splitting events in Neuroptera (Neuroptera: Nevrorthidae). Arthropod Systematics and Phylogeny 72 (2): 111-136

Tauber CA, Tauber MJ (1968) Lomamyia latipennis (Neuroptera, Berothidae) life history and larval descriptions. Canadian Entomologist 100: 623-629. doi: 10.4039/Ent100623-6

Tillyard RJ (1916) Studies in Australian Neuroptera IV. The families Ithonidae, Hemerobiidae, Sisyridae, Berothidae, and the new family Trichomatidae; with a discussion of their characters and relationships, and descriptions of new and little-known genera and species. Proceedings of the Linnean Society of New South Wales 41: 269-332.

Tjeder B (1959) Neuroptera-Planipennia. The Lace-wings of Southern Africa. 2. Family Berothidae. In: Hanström B, Brinck P, Rudebec G (Eds) South African Animal Life. Vol. 6. Swedish Natural Science Research Council, Stockholm, 256-314.

Tjeder B (1968) The genus Mucroberotha TJED. and its systematic position (Neuroptera). Entomologisk Tidskrift 89: 3-18.

Toschi CA (1964) Observations on Lomamyia latipennis, with a description of the first instar larva. Pan-Pacific Entomologist 40: 21-26.

Wedmann S, Makarkin VN, Weiterschan T, Hörnschemeyer T (2013) First fossil larvae of Berothidae (Neuroptera) from Baltic amber, with notes on the biology and termitophily of the family. Zootaxa 3716 (2): 236-258. doi: 10.11646/zootaxa.3716.2.6

Whalley PES (1980) Neuroptera (Insecta) in amber from the Lower Cretaceous of Lebanon. Bulletin of the British Museum of Natural History (Geology) 33: 157-164.

Willmann R (1990) The phylogenetic position of the Rhachiberothinae and the basal sister-group relationships within the Mantispidae (Neuroptera). Systematic Entomology 15: 253-265. doi: 10.1111/ j.1365-3113.1990.tb00316.x

Winterton SL (2010) A new species of Stenobiella Tillyard (Neuroptera, Berothidae) from Australia. ZooKeys 64: 1-8. doi: 10.3897/ zookeys.64.403

Zimmermann D, Randolf S, Metscher BD, Aspöck U (2011) The function and phylogenetic implications of the tentorium in adult Neuroptera (Insecta). Arthropod Structure and Development 40: 571-582. doi: 10.1016/j.asd.2011.06.003 